SOCIAL JUSTICE AND CULTURAL HOLIDAY CELEBRATIONS IN THE EARLY CHILDHOOD CURRICULUM: PERCEPTIONS OF EARLY CHILDHOOD EDUCATORS

\author{
by \\ May Jolliffe \\ Bachelor of Arts, Psychology, Queens University, Kingston, 1985 \\ A Major Research Paper \\ Presented to Ryerson University \\ in partial fulfillment of the \\ requirements for the degree of \\ Master of Arts \\ in the Program of \\ Early Childhood Studies
}

Toronto, Ontario, Canada, 2012

CMay Jolliffe 2012 


\begin{abstract}
Author's Declaration
I hereby declare that I am the sole author of this major research paper. This is a true copy of the major research paper including any final required revisions as accepted by my examiners.
\end{abstract}

I authorize Ryerson University to lend this major research paper to other institutions or individuals for the purpose of scholarly research.

I further authorize Ryerson University to reproduce this major research paper by photocopying or by other means, in total or in part, at the request of other institutions or individuals for the purpose of scholarly research.

I understand that my major research paper may be made electronically available to the public. 


\title{
SOCIAL JUSTICE AND CULTURAL HOLIDAY CELEBRATIONS IN THE EARLY CHILDHOOD CURRICULUM: PERCEPTIONS OF EARLY CHILDHOOD EDUCATORS
}

\author{
(C) May Jolliffe \\ Master of Arts, Early Childhood Studies \\ Ryerson University 2012
}

\begin{abstract}
This qualitative study focuses on the celebration of cultural holidays in Early Childhood Education and Care (ECEC) settings. There is little Canadian literature exploring how Early Childhood Educators (ECEs) perceive cultural holidays, social justice, and multiculturalism. Indepth interviews were conducted with five ECEs representing a range of professional experience in the Greater Toronto Area. Thematic analysis of the data yielded three themes: belonging, curriculum approaches, and systemic barriers. Participants identified gaps in training and professional development and made recommendations for future work in this area. There is substantial literature support for the participants' views on the importance of social justice, the need to support and respect families, and increased knowledge about cultural holidays. The study suggests that ECEs need additional knowledge and resources in order to successfully implement socially just cultural holidays.
\end{abstract}

Key words: anti-discrimination; multicultural; social justice; cultural holiday celebrations; curriculum 


\section{Acknowledgements}

Jaan and Lia, Thank you for your love and support through this challenging journey. This degree is a dream come true for me and you were both with me all the way.

I would like to thank Dr Marni Binder, my research supervisor for sharing her knowledge, inspiring me to achieve greater insight and for her untiring support throughout this process. To Dr Kathryn Underwood my second reader, thank you for helping me to articulate my research topic and for sharing your knowledge at key stages of this project.

I also owe thanks for the following Ryerson professors: Dr Mehru Ali for your leadership through the MRP writing seminar; Dr David Ruffolo for giving me the language and the tools to understand and address inequity and Dr Aurelia DiSanto, for your guidance as I began my graduate school journey.

Dr Selia Karsten, my good friend and fellow academic, I am thankful for the Sunday afternoon scholarly talks.

To my family, friends and colleagues from all parts of my life who have journeyed with me, I am so thankful for your unfailing encouragement, interest and inspiration. I could not have done this alone. 


\section{Dedication}

I dedicate this work to my daughter Lia whose courage and leadership shines through every day and to the children in my world who I am confident will become our future leaders in equity and social justice. Allison, Autumn, Avery, Cassie, Diego, Dillan, Elias, Kate, Lin, Madison, Mackenzie, Megan, Ravee and Ryan, I hope that you grow up to embrace your diverse communities with the same joyfulness that you show today. Each and every one of you inspires me to continue this work. 


\section{Table of Contents}

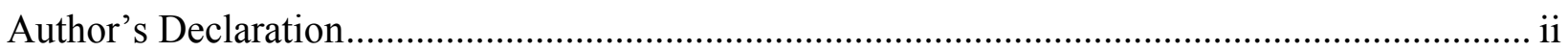

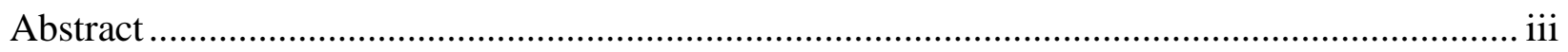

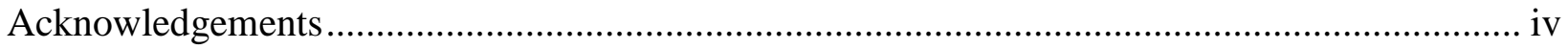

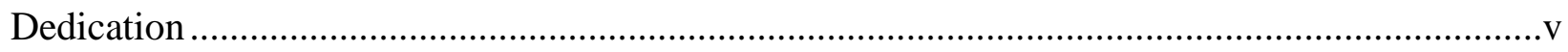

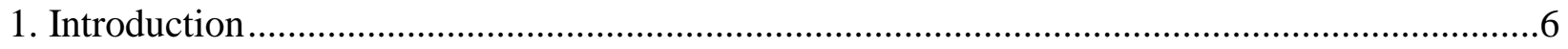

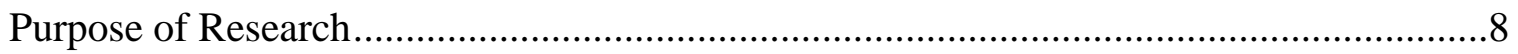

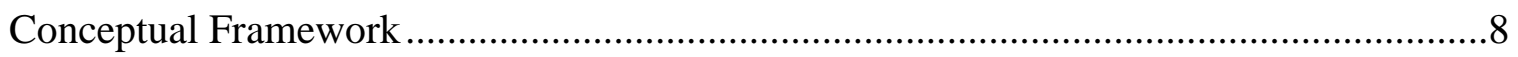

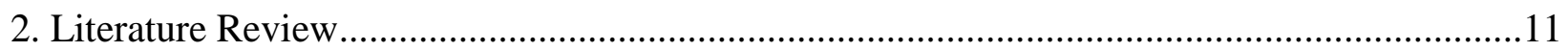

Gaps Identified in the Literature ………………….....................................................11

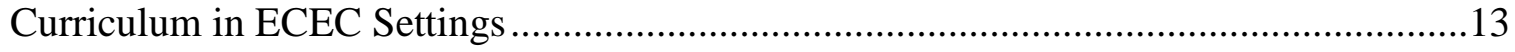

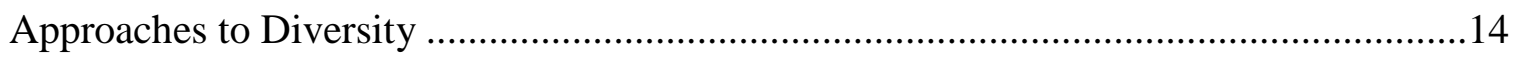

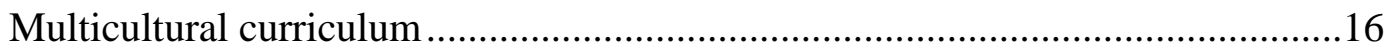

Criticisms of the multicultural curriculum approach ...........................................17

Anti-discrimination curriculum ..................................................................... 18

Why are Holiday Celebrations a Problem? ....................................................................20

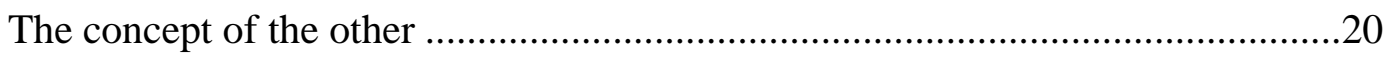

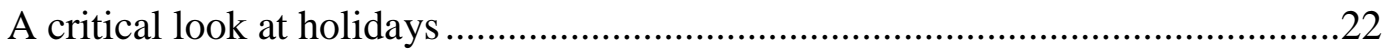

The problem with symbols..............................................................................23

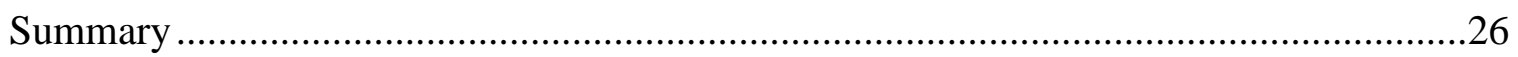

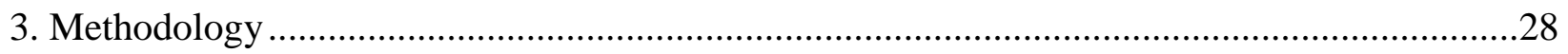

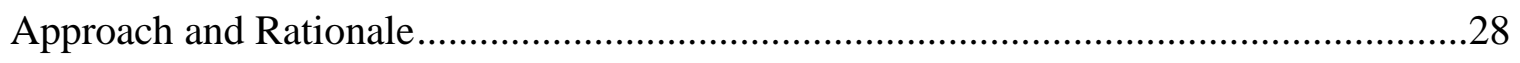

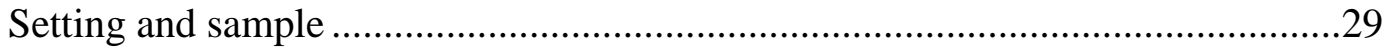


Strategy

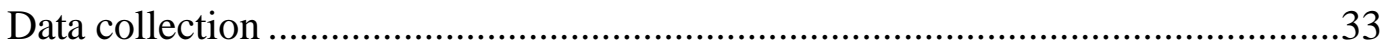

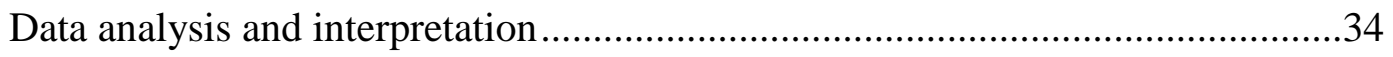

Authenticity and trustworthiness ...................................................................36

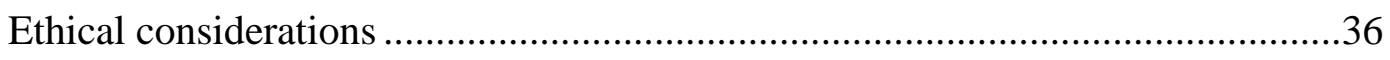

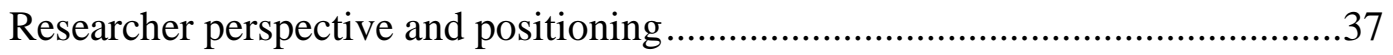

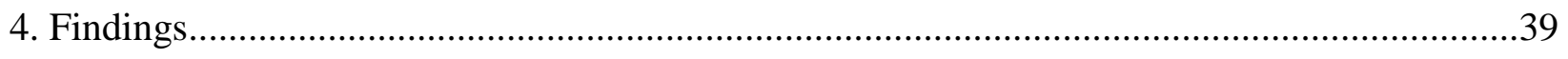

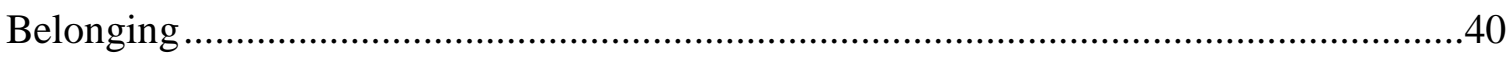

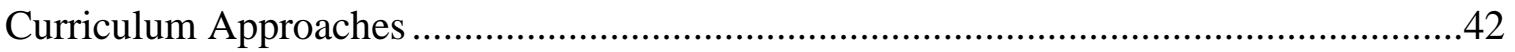

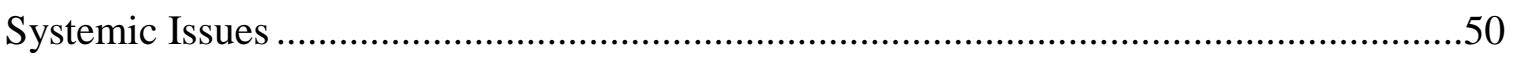

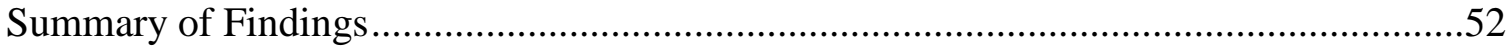

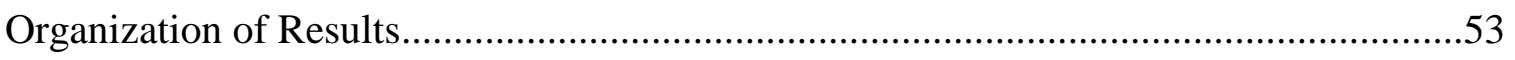

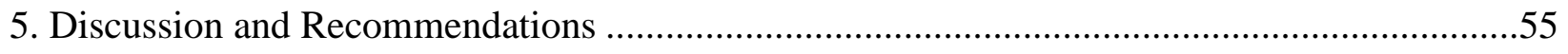

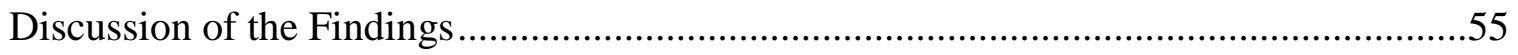

Marginalization of families .............................................................................56

The creation of the other ...................................................................................57

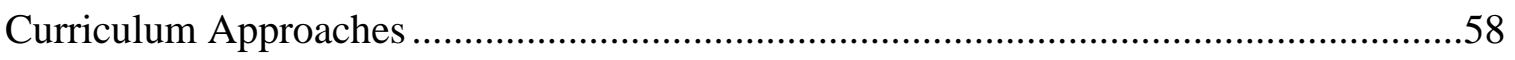

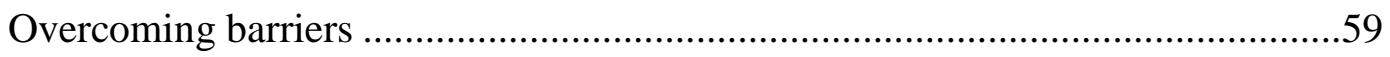

Suggestions for Future Research ............................................................................61

Implications for Policy and Practice …………………............................................62

Limitations of the Study..........................................................................................63

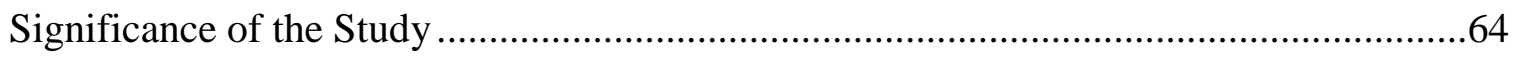

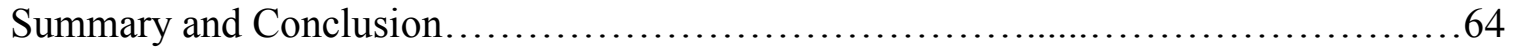




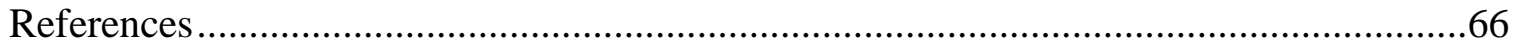




\section{List of Tables}

Table 1: Cultural Diversity: Schools of Thought within ECEC ..............................................14

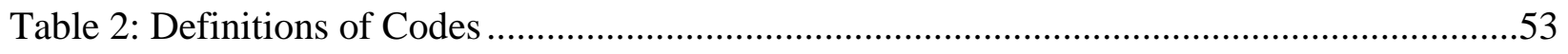




\section{List of Appendices}

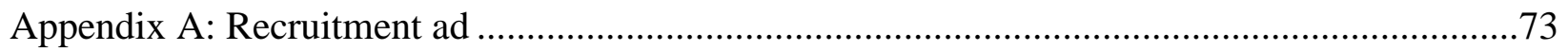

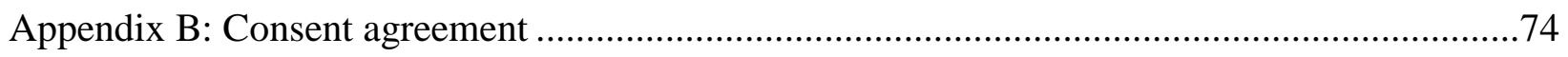

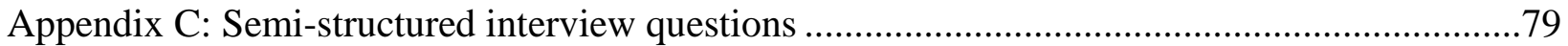

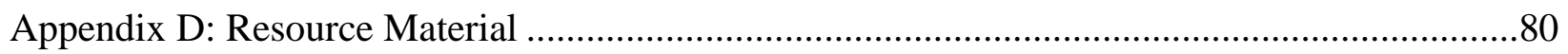




\section{Introduction}

One October day a number of years ago I observed a group of kindergarten children in a wealthy urban enclave wearing paper and feather headdresses. As I passed by, they shared their plan with enthusiasm. They were on their way to a nearby ravine to 'find Indians'. Upon further investigation, I was informed that the costumes and trip into the woods was a planned Thanksgiving curriculum activity. This vignette has stayed with me although until I became immersed in this research, I didn't fully understand the background or the implications of this activity. In retrospect, I can see that it may have been a well-intended but misguided attempt to present multiculturalism through a holiday celebration. A poststructural view of this activity would focus on the unspoken messages beneath the colourful feathers and the walk in the woods, binary messages about what is normal and powerful and what is exotic or different and inherently less powerful within society (MacNaughton, 2005). It serves as a reminder to me of the layers of powerful social messaging inherent in the planning and implementation of holiday celebrations in Early Childhood Education and Care (ECEC) settings. Early Childhood Education and Care is described by Friendly and Prentice (2009) to include regulated child care, nursery school and publicly funded kindergarten programs.

Research indicates that children develop an awareness of racial identity in early childhood including an awareness of groups in power (MacNaughton \& Davis 2009; DermanSparks \& Ramsey, 2011). This makes it particularly important for educators to ensure that holiday practices are inclusive, respectful, and equitable. As Derman-Sparks (2009) posits: "Across all dimensions of diversity, children absorb the images, stereotypes, and power differentials that are part of the fabric of their social milieu" (p. 128). Friendly and Prabhu (2010) argue that ECEC programs "have the capacity to be a main vehicle for providing environments 
in which young children can develop positive ideas about diversity as a foundation for lifelong tolerance and acceptance of difference" (p.9). While cultural holiday celebrations within the Early Childhood Education and Care curriculum have not necessarily been the focus of literature on equitable practices, the question of whether adding multicultural holidays and events is supportive of families and children or acts to marginalize them been noted by many theorists including Delpit, 2000; hooks \& Mesa-Bains, 2006; Lindsay \& Scales 2005 \& MacNaughton, 2006. Throughout this study, the connections between social justice and holiday practices within the curriculum will be interwoven. While this study is primarily about holiday celebrations, a small part of the ECEC curriculum, our attention is drawn to larger social justice issues, which warrant a more extensive discussion which is beyond the scope of this paper. The context of this discussion will be established by defining curriculum and social justice within ECEC and reviewing approaches to diversity within the curriculum.

Early Childhood Education and Care (ECEC) programs provide services to diverse populations. Families using these services may include members of one or more racial group and/ or cultures. In the Greater Toronto Area where this study was based, $43 \%$ of the population identified as visible minorities and 5\% of the population identified themselves as Aboriginal in 2006 (Statistics Canada, 2006). Social justice refers to the work that is done to create a fair and equitable society, one that combats marginalization, racism, prejudice, and imbalances in power (Delpit, 2006; Pohan, 2000). It is also described as "social responsibility" (Grant \& LadsonBillings, 1997). Within a diverse community, holiday practices may serve to highlight cultural stereotypes, further separating families and children who are not members of what has been termed a dominant North American culture (Derman-Sparks and Ramsey, 2011; Dorris, 2011; Mackey, 1998). Kumashiro (2000) uses the term "Other" to refer to those groups that are 
traditionally marginalized in society". He argues that these marginalized groups include students of colour as well as students from non-Christian religious backgrounds. It is hoped that through this work, there will be an increased awareness of the connections between curriculum practices and social justice.

\section{Purpose of Research}

The purpose of this qualitative research study was to determine the perceptions of social justice by Early Childhood Educators. The focus is on their views of multiculturalism and social justice in relation to cultural holiday celebrations within their professional practice. This research may be valuable for ECEs, policy makers and training institutions as it contributes to knowledge about the relationship of social justice to curriculum.

The questions guiding this qualitative research study are:

1) What are Early Childhood Educators' perceptions of social justice and multiculturalism? How do they perceive cultural holiday celebrations within the context of social justice and multiculturalism?

2) How do Early Childhood Educators perceive the role of families when planning holiday celebrations?

3) What are the gaps in training and professional development related to social justice and curriculum planning?

\section{Conceptual Framework}

Social justice provides the overall context for this study. Definitions of social justice refer to the work that is done to create a fair and equitable society, one that combats marginalization, 
racism, prejudice, and imbalances in power (Delpit, 2000; Landreman, Edwards, Balon \& Anderson, 2008; Mitchell, 2009).

A poststructural questioning of discourses guides my philosophical approach to this research. (MacNaughton, 2005, 2006). In writing about Foucault as applied to Early Childhood Studies, MacNaughton (2005) suggests that we "read for equity ... to explicitly insert issues of power and inequity into our understandings of the world" (p. 49). Poststructuralism goes beyond socially constructed knowledge to explore subjectivity and power relations. In poststructural theory, it is proposed that there are always ideas, groups, and concepts that are considered more desirable or more powerful in a society. Poststructural theory does not, however reflect the complexity of everyday life for families within ECEC. It is recognized that families described in this paper are not one dimensional but represent multiple cultures and multiple identities and that power is contextual. A powerful group may then be defined by comparing it to another group which is by definition less powerful. These hierarchical pairs are termed binaries and they depend on each other for meaning. One example of binary pairs is rich (powerful) versus poor (less powerful). The term dominant culture is sometimes used to reflect values and practices of more rich and powerful groups in the world or marginalized groups described earlier based on the work of Kumashiro (2000Throughout this paper, I have attempted to practise 'reading for otherwise' which "involves imagining how people other than the cultural and racial elite and the privileged might understand issues" (MacNaughton, 2006. p. 51).

Later in this paper, a sampling of popular children's holiday celebrations will be deconstructed to expose the underlying messages which may be contributing to the marginalization of families. Derman-Sparks (2011) suggests that children "notice, absorb, and enact the patterns of racial and economic privilege that permeate their environments..." (p. 45). 
Holiday celebrations play an important role in the ECEC curriculum. If the emphasis is on a dominant culture's holidays with celebrations that are not part of Christian and European traditions ignored or treated in a superficial or erroneous way, children may absorb messages about what is important and what is not. Ang (2010) refers to "the critical role of educational institutions and educators, whose practices and beliefs about culture can limit or extend the educational experiences of young children" (p. 42). 


\section{Literature Review}

There is little Canadian literature addressing cultural holiday practices in Early Childhood Education and Care (ECEC) settings. Most curriculum literature focuses only indirectly on social justice within the curriculum, originates outside of Canada and/or focuses on elementary and secondary education systems. MacNaughton (2006) argues that there is "little research support for early childhood professionals who wish to advocate among colleagues, parents and policy makers for an anti-discrimination approach" (p. 48).

Cultural holiday celebration is a term used in this study to refer to any special event celebrated as part of the curriculum in Early Childhood Education and Care settings. These events could include religious as well as cultural celebrations both inside and out of the commonly celebrated European and North American traditions (Hobsbawm, 1983; Sensoy, Sanhera, Parmar, Parhar, Nosyk \&Anderson, 2010).

The celebration of holidays as part of the ECEC curriculum can be viewed as problematic on a number of levels. On the surface, such events are often used to signal that a program is multicultural, inclusive, and antiracist (Derman-Sparks, 2011, hooks \& Mesa-Bains, 2006). Symbols including food, clothing, and artifacts are key components of holiday rituals and may be used to represent a culture although in many cases these symbols may be stereotypical and/or inauthentic (hooks \& Mesa-Bains, 2006; MacNaughton, 2006).

\section{Gaps Identified in the Literature}

The gaps in the literature on social justice and curriculum are identified by Clark and Shimoni (2000) who identify the need for research on the relationship between a weak Canadian identity and a sense of insecurity experienced by ECE students about integrating cultural 
practices within the curriculum. In an Australian context, MacNaughton and Davis (2001) note that "little (if any) research has focused on how an early childhood practitioner plans and implements teaching about indigenous Australians and their culture" (p. 84).

The need to define competencies (for diversity and equity) within the broader ECEC system is stressed in the report developed by the working group on Diversity and Social Inclusion: Exploring Competencies for Professional Practice in Early Childhood Education and Care (Diversity in Early Childhood Education and Training and International Step by Step Organization, 2011). It has been argued that in order to address issues of social justice and injustice, we need to deconstruct traditional views and practices and to examine the relationships of power hidden beneath these traditions (Canella, 1997; MacNaughton, 2006). Kumashiro (2000) has recommended that poststructuralist approaches can support educators in addressing "the multiplicity and situatedness of oppression and the complexities of teaching and learning" (p. 25). The literature on curriculum and cultural celebrations speaks to the need for new knowledge that is relevant not only to agencies but to ECE practitioners and families.

This cross-disciplinary review of the literature also provides the theoretical, historical and socio-cultural context for the study. It also includes other scholarly work which informs the overall discussion of holiday practices as they intersect with culture, religion, ethnicity and race. Cultural holidays within ECEC programs need to be examined within both a historical and a societal context. The literature suggests that much work still needs to be done to ensure the larger concepts of multiculturalism, racism, and equity are relevant to ECEC settings (Derman-Sparks, 1989; Derman-Sparks, 2011; MacNaughton \& Davis, 2009). 


\section{Curriculum in ECEC Settings}

This study will focus on the relationship between social justice and curriculum in Early Childhood Education and Care settings. The operational definition of curriculum to be used in this study is "the content of what is taught and what is learned" (Kagan \& Kaurz, 2006, p. 2). It is recognized that this definition artificially separates the actual day to day events such as holiday celebrations from overarching beliefs and pedagogy. This study will focus on curriculum rather than pedagogy, recognizing that curricula are influenced by changing world views and pedagogical approaches but are a reflection of these views and do not stand alone (Papatheodorou, 2010).

A curriculum approach commonly termed an inclusive curriculum can have multiple meanings in theory and in practice, especially within the field of Early Childhood Education (Kumashiro, 2000; MacNaughton \& Davis, 2001; Mitchell, 2009). This variation between terms and meaning can give rise to a patchwork of practices, many of which are not consistent with a stated philosophy of anti-racism and inclusion. The practice of holiday celebrations has been chosen for further examination as it is a component of the curriculum which is often presented as joyous and inclusive yet may be divisive and oppressive. The next section will provide an overview of approaches to diversity within the curriculum identified by MacNaughton, (2006). The American term "anti-bias approach" falls under the umbrella of the anti-discrimination school according to MacNaughton (2006, p. 45). The term "anti-discrimination" will be used throughout this paper. This will be followed by a discussion about the multicultural and the antidiscrimination approaches to curriculum. 


\section{Approaches to Diversity}

Cultural holiday celebrations are inextricably intertwined with the broader issues of equity and diversity documented by MacNaughton (2006). In a literature review entitled Respect for diversity: An international overview, MacNaughton identifies five schools of thought related to diversity in early childhood settings. These classifications, discussed below with examples related to culture, racism, and holiday celebrations are important in situating current Canadian practices.

Table 1: Cultural Diversity: Schools of Thought within ECEC

\section{Laissez-faire}

Characterized by equal treatment, sameness is emphasized. It is also known as the colour blind approach. Equity is the stated goal.

2. Special provisions

Children are helped to meet the established norm. Focus is on achieving cultural competency within the dominant culture.

3. Cultural understandings

The focus is on helping mainstream children to understand and tolerate differences. Cultures other than the dominant one are represented in stereotypical or tokenistic ways.

4. Equal opportunity

This approach is based on a belief that everyone can succeed if they have access to opportunities within society. The focus is on children`s strengths. Classroom displays which would be represented in the classroom environment 


\section{Anti-discrimination}

Also known as critical or transformative education, the goal is to combat inequity and injustice. Diversity is woven throughout the curriculum through aesthetics, materials and learning experiences.

Adapted from MacNaughton (2006, pp. 29-39)

Holiday practices within the laissez-faire, cultural understandings and equal opportunity school approaches would share similarities in their superficial approach to holiday practices. Derman-Sparks (2009) refers to this as a "tourist curriculum" (p.115). Within the laissez-faire approach, racial differences are not acknowledged. Holiday practices would then be unexamined. The cultural understandings approach would logically focus on the introduction of lesser known holidays, those practiced by other cultures. The special provisions approach may include immersion programs and support for children to achieve competency within the dominant culture of their community. There can be an implication that that they are deficient if this is not achieved (MacNaughton 2006). It would follow that the emphasis would be on dominant culture holidays if the goal is for children to become proficient in these practices, what Delpit (2006) terms "the culture of power" (p. 25). The equal opportunities approach as described by MacNaughton (2006) focuses on success within the dominant culture. Holiday practices would logically reflect a range of cultural representations including holidays consistent with a surface approach to multiculturalism.

An analysis of the above approaches (described in Table 1) to multiculturalism results in the identification of common themes. The laissez-faire school, the colour blind approach, the cultural understandings approach, and liberal multiculturalism all ultimately emphasize the dominant culture as the norm (MacNaughton, 2006). Varying degrees of diversity may be seen in 
areas such as holiday celebrations and displays. Ghosh (1996) refers to "the study of 'exotic' cultures, in 'multicultural days' ... practices which have developed from approaches which ignore difference (p. 1). These approaches do not address structural inequities within education or society (Banks, 2008, Dei, 2003; MacNaughton, 2005).

The difference between the multicultural activity approach and an approach that goes beyond activity to address underlying issues is articulated by Dei (1996). He argues that Anti-racism calls for putting power relations at the centre of the discourse on race and social difference.... While the notions of culture(s) and cultural differences are relevant to anti-racism discourse, it stresses that a romanticized notion of culture, which fails to critically interrogate power, is severely limited in the understanding of social reality (pp. 26-27).

In the context of ECEC settings, MacNaughton (2006) identifies a cluster of practices as belonging to the anti-discrimination school of thought. While there are regional differences in approach and names, all share a commitment to addressing the systemic roots of racism and equity. While this study is focused on curriculum practices, it is valuable to be aware of the larger discourse on diversity including pedagogy, culture and power, especially in a Canadian context. The differences between a multi-cultural curriculum and an anti-discrimination curriculum are discussed below.

\section{Multicultural curriculum.}

Ghosh (1996) provides a historical context for multicultural education within the Canadian educational system. Early implementation of multicultural education focused on assimilation of newcomers into the dominant English and French culture. It then evolved to include the study of other cultures within the curriculum and work to have teachers reflect the 
broader school population. Ghosh describes the broadening of multicultural curriculum to include "world views different from the traditional male, middle class Eurocentric bias" (p. 18). While the focus of Ghosh's work is on the educational system, it is relevant to the development of anti-discrimination curriculum within ECEC. Integral to an anti-discrimination approach is not only awareness, but a willingness to transform pedagogical and curriculum approaches. MacNaughton (2006) describes the successful outcome: "all children learn to champion fairness, respect diversity and build self-esteem" (p. 48). Jacobsen (2003) defines a multicultural curriculum as one that focuses on ethnic culture while an anti-bias [anti-discrimination] curriculum addresses "different kinds of bias including gender, sexual orientation, culture and abilities...” (p. 30). Derman-Sparks (2009) describes multicultural education within Early Childhood Education as an approach which was developed to strengthen respectful relationships among racial and cultural groups, an approach consistent with Ghosh.

\section{Criticisms of the multicultural curriculum approach.}

Shortcomings of the assimilation (Ghosh 1996) or melting pot vision of multiculturalism within education are highlighted by Derman-Sparks (2009). She describes the shortcomings of an approach designed to have all cultures influence a common vision while in reality the European worldviews have had the strongest influence. The core constructs of the assimilation vision are also identified in what MacNaughton characterizes as the cultural understandings (tokenistic) approach to diversity (2006). Ang (2010) suggests that these approaches may be overly simplistic and "emphasize[s] the similarities between cultures, but without engaging in depth with the issue of cultural difference" (p. 46). Ang refers to "unequal social structures" and acknowledges the challenges "of trying to deliver an appropriate curriculum and to make such complex issues meaningful for themselves and young children without trivializing them" (p. 49). 
Ang (2010) criticizes any approach that does not address the power relations or the complexities inherent in these approaches. Of particular concern is the fact that in Britain "few individuals can identify themselves as a member of a single cultural or racial group..." (p. 47).

Derman-Sparks (2009) further argues that the very shallow approach to a multicultural curriculum is at the heart of its appeal. "Because add-on multiculturalism is organized around concrete and nonthreatening activities (e.g., food, holidays, songs), many teachers find it easier to make these superficial gestures or window dressing changes rather than to truly transform their curriculum" (p. 131). Neito (2002) notes that multicultural education is generally considered to be added curriculum content using examples ranging from the addition of bilingual/bicultural programs or "simply the addition of a few 'Holidays and Heroes' to the standard curriculum" (p. 7).

\section{Anti-discrimination curriculum.}

The boundary between a multicultural curriculum and the anti-discrimination school approach can be described as the difference between acknowledging differences and asking what it means to respond to differences (Dei, 2003). The anti-discrimination approach is also known as critical or transformative education. "They [educators] aim to transform the people, institutions and ideas that produce inequity and injustice" (MacNaughton, 2006). Included under the anti-discrimination school umbrella, MacNaughton (2006) includes a description of antiracist education, a term used in Australia. Anti-racist education which takes a societal approach to addressing racism while encouraging individual actions. While MacNaughton (2006) uses the terms anti-bias and anti-discrimination to describe the Canadian and American implementation 
of work initiated by the Anti-bias Task Force, she acknowledges that "the principles are still evolving" (p. 45).

Holiday celebrations evolve from the children's knowledge base and every effort is made to ensure that practices are respectful, authentic, and free of stereotypes. As the curriculum would be rich in diversity every day, holidays may not necessarily be special events. It should be noted that an anti-bias approach differs from an anti-discrimination approach as the former suggests that bias can be addressed and changed. Bias in this context is considered to be negative as with the goal of an anti-bias curriculum is to reduce bias and increase tolerance of diversity (MacNaughton 2006). Kelly and Brandes (2001) argue that "teacher neutrality" (p. 8) is a widely accepted ideal for teachers and that bias "implies a prejudice or favouritism, something to be avoided" (p. 8). The need for further research on the relationship between curriculum and bias is also stated by MacNaughton (2006). In an ECEC setting, discussions of bias would extend not only to the children but to the teachers. There is limited research on training models focused on moderating teachers' attitudes toward diversity (MacNaughton, 2006).

Ang (2010) argues that equality and equity are not necessarily addressed within the antibias (Derman-Sparks, 2011) or anti-discrimination (MacNaughton, 2006) curriculum approaches. She refers to the "rhetoric of policy and curriculum documents...premised on the supposition of valuing inclusivity and cultural diversity [while] in reality children often witness and experience inequality daily" (Ang, 2010, p. 49). MacNaughton (2006) acknowledges that to be successful, an anti-discrimination approach would need a strong commitment from practitioners as well as sufficient resources to support implementation. The ways in which an unexamined curriculum can hide inequality are part of the upcoming discussion on celebrations. 


\section{Why can Holiday Celebrations be a Problem?}

It is important in social justice work to become aware of the often unseen dynamics, the messages which support discourses which MacNaughton (2006) terms day to day accepted truths. MacNaughton (2006) describes these meanings as texts, using examples such as "books, songs or images used in daily work with children" (p. 76). Holidays are an accessible and concrete way of examining social justice within ECEC. They are, however just one component of social justice within ECEC. Changes to holiday practices alone cannot rectify social injustices. For a child whose family's cultural and/or religious holidays are out of step with those celebrated in ECEC, they can feel isolated. It is described in the first person by Syal, (as cited in Ang, 2010, p.1) "But no one else in the world seemed to care that today was our Christmas ... and nobody, not one person, had wished me a happy Diwali”.

\section{The concept of the other.}

Kumashiro (2000) uses 'the term 'Other' to refer to those groups that are traditionally marginalized in society, i.e., that are other than the norm, such as students of colour ...” (p. 26). Kumashiro argues that further research is needed to explore the connections between Othering and students from non-Christian religious backgrounds. Mackey (1998) proposes that some cultural events are accepted as Canadian or white without being named as such (p. 107). “Cultural specificity was not marked out as salient except when the cultural activities were not ‘just plain Canadian’ but were other’ (Mackey, 1998, p. 107). Kumashiro (2000) notes that teaching students about the 'other' is an example of oppression of cultures. It follows then that the pedagogical practice of stereotypical holiday practices could lead to marginalization of families and children. 
Ang (2010) addresses the challenge in defining culture but suggests that an inclusive definition of culture can be termed "ordinary" or a "way of life" (p. 42). Culture has also been referred to as "history and experiences, norms and values" (DECET 2011, p.10). Clark and Shimoni (2000 suggest that "the Canadian identity includes the interweaving of many cultures" (p. 59). The idea that a white culture exists has been explored by Davis, 2009, Ghosh, 1996 and Mackey, 1998. Davis (2009) emphasizes that in order to “...construct relationships with children families and colleagues that are equitable and socially just, educators, especially white educators must work to see their own culturally diverse mix" (p. 114). Clark and Shimoni (2000) identify the struggle for ECE students to grapple with the challenge of determining whether there is a Canadian culture and where they situate themselves within it.

Rhedding-Jones (2001) argues that educators must take a critical approach to holidays, recognizing the complexity and the diversity within families as well as within cultural groups. Research has demonstrated that the presence of holiday and celebratory symbols which represent a dominant culture can adversely affect the well-being of members of non-dominant cultures (Munson, 2011; Schmitt, Davies, Hung \& Wright, 2010). Dorris (2011) a parent of three Native American [sic] children highlights his concerns regarding stereotypes and the negative impact they have on his family: "With depressing predictability, my children have been variously invited to 'dress up and dance,' portray Squanto...and ‘tell a myth”' (p. 103). Munson (2011) highlights the negative impact of stereotypical logos depicting Native Americans. She argues that if we accept these stereotypes, we are teaching all children to tolerate racism. Rhedding Jones (2001) argues that if it is assumed that there is a holiday for everyone during the Christmas season, whatever it is named, we are reinforcing difference. In the above examples, children and 
families are impacted by these unexamined practices which establish in subtle ways what is accepted and what is not accepted.

\section{A critical look at holidays.}

Woven throughout the above discussion on social justice and curriculum are explorations of oppression (Kumashiro, 2000), respectful relationships with families, (Ghosh, 1996), and curriculum approaches (Derman-Sparks, 2011, MacNaughton, 2006). These concepts will be explored through a critical look at a sampling of celebrations. This exploration of celebrations is not necessarily representative of practices across a culture nor is it intended to suggest that any one celebration is better in relation to another. The intention of this analysis is to encourage the reader to question accepted practices.

Hobsbawm's (1983) seminal work on the creation of traditions takes a critical look at holidays, describing invented tradition "to mean a set of practices, normally governed by overtly

or tacitly accepted rules and of a ritual or symbolic nature, which seek to inculcate certain values and norms of behaviour by repetition, which automatically implies continuity with the past" (p. 1). This is consistent with Delpit's (2006) description of "codes and rules" that are embedded within the education system (p. 24).

As discussed in the context of a "culture of power" (Delpit, 2006), cultural holidays may serve the purpose of establishing and maintaining values and norms, in this case as part of the curriculum in ECEC settings. This concept of ‘invented tradition' (Hobsbawm, 1983) resonates with the framework of poststructuralism as it captures the idea that reality has been constructed or invented. The next section will take a critical look at some of the themes common to some popular cultural celebrations as they relate to ECEC. 


\section{The problem with symbols.}

Symbols are a key part of holiday celebrations, especially within ECEC settings. As we will see in the following examples, these symbols may not be authentic and in some cases reinforce cultural and/or racial stereotypes. This discussion builds on the work of Fryberg, Marcus, Oyserman and Stone, (2008); Ghosh (1996); and Schmitt et al. (2010), but in this case examining holiday symbols typical to ECEC settings. Schmitt et al (2010) argue that dominant holiday symbols establish the norm. Decorated evergreen trees in December, pumpkins in fall and pastel eggs in spring can be seen throughout the community and in ECEC programs. They are rarely labelled as their meaning is assumed. This supports the idea that symbols are a type of code (Delpit, 2006).

Images of Canada often rely on representations of Aboriginal people and culture (Francis, 2004). Francis writes about the "images of Native people that White Canadians manufactured, believed in, feared, despised, admired, taught their children" (p. 4). Dorris (2011) calls it "Indian Fakelore [sic]" (p. 100). Munson (2011) proposes that over time and with practice, generations of children have come to believe that the pretend 'Indian' identity is more than what it is" (p.150). Stereotypical images, both positive and negative, are then reinforced through advertising, literature, and children's holiday activities as described in the introduction to this paper.

Another symbol, the fortune cookie, a centrepiece of ECEC Chinese New Year celebrations, was actually developed by a San Francisco noodle factory as a tourist promotion (Yeh, 2004). It is often accompanied by elaborate costumes and parades. The deconstruction of this exotic presentation of China, reflected in exotic, stereotypical presentations of rituals, 
clothing, and food reveals the intent behind the presentation. The events were developed by the Chinese community for the dual purposes of tourism promotion and the diffusion of racial tension (Yeh, 2004). It is interesting then to compare the description of constructed rituals, to Yeh's descriptions of earlier, localized community events and to stories my grandfather told me of his experiences in West China as preparations for the New Year focused on themes of reconciliation and restitution.

Representations of Christmas are easily recognizable and are considered one of many examples of symbols. The Christmas tree, described by Schmitt, et al. (2010) as a symbol of the dominant culture is seen throughout public spaces each year during late fall signalling the beginning of the holiday season. The dominance of Christmas and its influence on non-Christian cultures, in this case Judaism, is demonstrated by Abramitzky, Einav and Rigby (2010). Their study shows a quantitative relationship between expenditures by Jewish families at Hanukkah when they live in an area where Christmas is the dominant holiday. This is highlighted by the examples of Hanukkah when American Jewish families with young children celebrate Hanukkah with an intensity which is significantly out of step with the minor religious significance of the holiday. "Hanukkah is often called the 'Jewish Christmas' because American Jewish parents give their children gifts, like their Christian neighbours" (p. 612). Although this study is based in the United States, it is consistent with experience within my professional practice. I have observed the emphasis on Hanukkah as an alternative to Christmas especially when Hanukkah occurs close to the end of December. The more important religious holidays of Judaism may then pass by unacknowledged.

Kwanzaa holiday celebrations seem like an appealing way to include families of African heritage at Christmas time. "Designed to resemble the ritual at an African harvest festival, 
Kwanzaa consists of a number of activities, from feasting and lighting candles to recitations and the giving of small gifts to children" (Pleck, 2001, p. 3). A look beyond the surface, however, reveals a complicated and contradictory history which speaks to the need for an understanding of the appropriate and respectful way to celebrate this holiday. Kwanzaa originated as did many holidays as what Hobsbawm (1983) refers to as an invented tradition. From its political origins in the American Black nationalist movement, it has become part of North American mainstream culture and consumerism. Original, handcrafted symbols of Kwanzaa have in many cases been replaced with commercial representations (Mayes, 2009). If Kwanzaa (as one example of a holiday) is uncritically presented as a 'one- size- fits- all' companion holiday to Christmas, we may not be respecting and honouring the diversity within our communities. Instead, we may be engaging in a non-critical multiculturalism, one that mistakes specific and sometimes value laden knowledge about individual cultural practices for cultural competency (Dei, 2003; Diversity in Early Childhood Education and Training \& International Step by Step Organization, 2011; MacNaughton, 2006; Derman-Sparks, 2009).

The deconstruction of a sampling of holidays highlights some of the paradoxical origins and unexamined messages embedded in cultural holidays. Inauthentic holiday practices can become embedded through replication and be accepted as truth, a socially constructed and marginalizing reality of the other (Derman-Sparks, 2011). Britzman, Santiago-Valles, JimenezMunoz and Lamash (1993) bring attention to the stability reflected in our images of the other, the presentation of a non-critical and one- dimensional view of non-dominant cultures. This presentation is in contrast to the unstable structures and fluidity of poststructuralism: "These newly represented cultures appear on the stage of curriculum either as a seamless parade of stable and unitary customs and traditions or in the individuated form of particular heroes 
modeling roles” (Britzman et al., 1993, pp. 188-189). This argument is reiterated by Sensoy, Sanhera, Parmar, Parhar, Nosyk and Anderson (2010) in a Canadian educational context. They argue that the additive multi-cultural discourse does not address current inequities in society but rather treats inequities as historical events while celebrating the surface differences of other [non-Canadian] cultures.

Etzioni (2000) suggests that in changing and diverse societies, rather than leading societal change, holidays and rituals lag behind. This view provides some insight into the prevalent archetypal approach to holiday celebrations in ECEC settings. We can now see some linkages between curriculum approaches with a reliance on regular, ritualized celebrations or an approach informed by children's interests and lived experiences. The following section discusses curriculum approaches within the literature that would further our goals of supporting children and families in socially just communities.

\section{Summary}

The literature demonstrates that children thrive when the common threads of teacher selfawareness, a social justice lens in day-to-day teaching, and respect for home language and culture are part of the curriculum. Dei (1996) suggests that we draw upon the strengths of individuals and the community to work toward transformative change. This goal can be addressed in a number of ways, including research models that include the voices of parents and communities (Ladson-Billings, 2001) and by creating the ideal school, "an affirming space where Otherness...is embraced, where normalcy...is not presumed" (p. 28). Dei (1996) describes such a transformation as "the adoption of deep curriculum" (p. 79). Ang (2010) argues that practitioners need support to become critical thinkers rather than to be provided with 
"generalized recommendations or sets of rules...concerning how to deal with issues of diversity". (p. 50).

The importance of preparing the educator to address the complexities of cultural diversity and inequity within the curriculum is recognized by Ang (2010) who argues that "professionals need to first develop a critical consciousness in the way we perceive and interpret the world" (p. 50). In contrast, Landreman et al. (2008) propose a curriculum framework for developing social justice educational competencies. This framework would identify specific learning (competency) outcomes, creating tools that allow individuals to assess their level of competence, and providing learning opportunities that facilitate acquisition of the competencies. The approaches of both Ang (2010) and Landreman et al. (2008) are focused on the educator, which underscores the importance of understanding the perspective of ECEs around diversity and equity.

Discussions of cultural holidays generally form a small part within the literature across a range of disciplines. This review has highlighted the intersections of curriculum, culture, and power within the field of ECEC and at a societal level. The part that holiday celebrations play in educational and social settings can serve to inadvertently establish and reinforce binaries between established cultural practices and the lesser known traditions and practices of other groups. This process, however well-intentioned can have negative effects on children and families (Burnett, 2001; Delpit, 2006; Dorris, 2011; Francis, 1992; MacNaughton, 2006; Schmitt et al, 2010). Real change can be effected not through policies and guidelines (Ang, 2010; MacNaughton, 2006; Sensoy et. al., 2010) but rather through a critical approach to curriculum. 


\section{Methodology}

\section{Approach and Rationale}

This research study used a qualitative approach to address research questions related to cultural holiday practices in Early Childhood Education and Care Settings. A qualitative approach was an appropriate choice of methodology for this study as it seeks to understand rather than quantify the perceptions of individuals within the ECE profession. Qualitative research can contribute to what MacNaughton (2006) describes as “spaces for 'other' ways of knowing and acting with children for social justice" (p. 43), a goal consistent with the topic and theoretical approach of this study.

Thomas and Magilvy (2011) use the metaphor of a hedgehog to describe a qualitative researcher: "[They] tend to focus their attention on depth by identifying a single phenomenon while burrowing deep ... to gain a deep understanding of a specific phenomena/experience with a limited number of participants" (pp. 151-152). The process of interviewing provided a rich data set reflective of some ECEs perceptions and experiences of social justice, multiculturalism and cultural holiday celebrations. Rubin and Rubin (1995) describe design in qualitative interviewing as iterative: "That means that each time you repeat the basic process of gathering information, analyzing it, winnowing it, and testing it, you come closer to a clear and convincing model of the phenomenon you are studying" (p. 46). This description parallels the process of building the structure of the study through interviewing, and theme development.

Thematic analysis (Boyatzis, 1998) will be used as the analytic framework as it supports a qualitative approach. Through thematic analysis, the goal is to develop insight into the perceptions of some ECE's regarding cultural holiday practices. Thematic analysis as described 
by Boyatzis (1998) is divided into three stages beginning with sampling and design issues (Stage I), continuing with the development of themes and code (Stage II), and lastly validating and using the code (Stage III). This iterative process supports the achievement of rigour which will be discussed in more detail later in this chapter. Approaches to the development of themes and code (Stage II) can be viewed as a continuum from theory driven to data driven. A theoretical approach would rely on existing theories or particular analytical interests of the researcher (Braun and Clarke, 2006). A data driven or inductive analysis approach would rely only on the data for the development of codes. Braun and Clarke identify "the data-driven" or "inductive" approach to analysis as occurring when data is coded in an open ended way without specific reference to the interview questions (p. 83). The analysis of the data could be described as midway on this continuum as opportunity to see the data obtained through the participant interviews with a fresh perspective, was influenced by the existing literature. There is a dearth of Canadian research specific to cultural holiday celebrations in ECEC. It is important to allow the data to dominate the analysis, leading to the development of themes. These themes are then related to the available literature.

\section{Setting and sample.}

The study focuses on the perceptions of Early Childhood Educators. Participants for the study are drawn from Early Childhood Educators who have experience within licensed children's programs in the Greater Toronto Area. The first phase of recruitment was initiated through an appeal to the Association of Early Childhood Educators of Ontario Peel and York branches and Child Development Resource Connection Peel (CDRCP) (Appendix B). This sampling technique is defined as typical case sampling (Flick, 2006, p. 130). A snowball sampling technique (Litchtman, 2006, p. 22) was also employed. Voluntary participants were asked to refer 
acquaintances to the researcher. Recruitment was initiated in October 2011 through the agencies described above. As of early December, the low level of responses from eligible participants necessitated a review of the recruitment strategy. The REB protocol was re-opened and approved to broaden the criteria for participation to include ECEs with experience with licensed child care either in a teaching, supervising, or consulting role. The sampling procedure was broadened to include Ryerson students in ECE and MAECS degree programs as well as acquaintances of the researcher. The requirement to be a current member of the College of ECE was modified to include ECE degree and Bachelor of Education students whose membership applications were in process. The second phase of recruitment included a presentation to a supervisor group of the $C D R C P$ and emails to contacts within the groups described above. Seven qualified participants expressed interest in the study; two of this group did not confirm participation. No volunteer participants were rejected.

The five participants in this study were assigned a pseudonym by the researcher. A range of experience in multiple settings in a variety of demographic and geographical contexts is represented by the participants in this study. Each participant described her experience in more than one ECEC setting. For most participants, their lens reflected multiple roles at different points of their career reflecting their work as an ECE student, teacher, supervisor or consultant. It is of interest that all participants were women and four out of five participants identified as parents. The research protocol and consent agreement state that the goal of the research is to learn more about the professional opinions of ECEs. The researcher subsequently did not ask any specific questions regarding ethnicity, race or country of birth. Some details did emerge naturally during the interviews and have been included in the introductions. All quotations are the words 
of the participants except where edited for readability. A short introduction to each of the participant follows:

Participant one: Carin is an ECE who has worked within the field as a teacher, supervisor, community college faculty and consultant. Her experience is in a wide range of suburban and rural settings within the Greater Toronto area. She is a member of the College of ECE and has completed graduate work in Early Childhood Studies as part of her career path.

Participant two: Giulia trained as an ECE at a community college and is a member of the College of ECE. She identifies her family as not being religious but that holidays were celebrated at home when she was growing up. She has experience in a range of urban ECEC settings. She currently works with school age children in an affluent area.

Participant three: Tasmin has worked as an ECE teacher in multiple urban settings. She is a member of the College of ECE. In addition to ECE training, she has completed graduate work in Early Childhood Studies.

Participant four: Sara is a new graduate and member of the College of ECE currently pursuing a teaching degree. She has worked as an ECE in child care programs during school breaks. She describes immigrating to Canada from the Caribbean with her parents as a young child. Her parents wanted her to become Canadian so they supported her participation in her first Halloween even though they didn't understand it. Sara's parents took her out on Halloween but did not give out candy from their home.

Participant five: Laura works as an ECE with preschool children in an enrichment program. A member of the College of ECE, she has over 15 years of experience in full day care and nursery school in both urban and rural settings. She describes her family as representative of multiple cultures.

\section{Strategy.}

Data was collected through semi-structured individual interviews, one variation of the indepth interview (Marshall \& Rossman 1989; Merriam, 1998). It is also described by Marshall 
and Rossman (2011) as "generic in-depth interviewing" (p. 146). A semi-structured interview can be viewed as conversational (Merriam, 1998). It can include structured as well as openended questions which can be introduced in any order. This approach encourages an emergent approach to the interview (Merriam, 1998). A mix of structured and open- ended questions was established. (See Appendix C). The researcher further probed key words (multiculturalism, equity, racism, and stereotyping), which are identified in the literature as key components of an examination of social justice. Examples of probes are "can you tell me more; if we added (key words) to this discussion, what would that look like; hmmm, interesting, can you tell me more; can you give me an example? This approach is consistent with a process described by Marshall and Rossman (2011) where the questions establish "a few general topics to help uncover the participant's views but otherwise respects the way the participant frames and structures the responses" (p.144).

Thematic analysis was chosen as the analytical tool for the study. Given that there is little published research on how ECE practitioners' perceptions of social justice are reflected in their practice, it is important to use an analytical approach that does not lock the data into preconceived themes. "Through its theoretical freedom, thematic analysis provides a flexible and useful research tool, which can potentially provide a rich and detailed, yet complex account of data" (Braun \& Clarke, 2006, p. 78). An inductive approach to analysis was used as the primary strategy as this allowed the data to lead the development of themes rather than basing themes on existing theories (Braun \& Clarke, 2006). This approach provides an opportunity for the perceptions of ECEs to be highlighted, a process that Boyatzis, (1998) refers to as the bringing forward of "previously silenced voices or perspectives inherent in the information" (p. 30). The 
literature on curriculum practices and social justice was also referenced in the development of themes and code.

\section{Data collection.}

Individual interviews with ECE practitioners formed the basis for data collection. These interviews followed a semi-structured format. The researcher introduced the intent of the study, specifically the need for more information about what Early Childhood Educators think about cultural holiday practices, multiculturalism and social justice. The participants were informed that they would be asked to describe actual holiday practices including how they were planned as well as their thoughts on multiculturalism and social justice. The final question would relate to their recommendations for professional development and training. The researcher described the interview format and completed the consent process. Participants were reminded that they could end their participation in the study at any time.

The semi-structured interview format was introduced to participants with an emphasis on the interactive intent of the interview, a structured conversation with flexibility in the ordering and answering of questions. Kvale (1996) describes this approach as "a conversation that has a structure and a purpose" (p. 6). The five participants interviewed for this study represented a wide range of educational backgrounds and experience in varying geographic and demographic locations. Kvale (1996) does not set out a minimum number of participants for qualitative studies but rather suggests that you "interview as many subjects as necessary to find out what you need to know" (p. 101). This is a subjective decision made by each researcher. In this case, four interviews was the minimum set out in the design of the study; the fifth interview provided further confirmation that the research question had been answered. 
All interviews were audio-recorded. Data included the date, time, location, name and pseudonym of the participant. This approach served to verify the origin of data used in the final report. Data was stored in a locked container under the care of the researcher during analysis. Transcriptions were destroyed once analysis was completed. A password protected electronic copy of data will be maintained by the research supervisor for two years.

\section{Data analysis and interpretation.}

Thematic analysis provided a structured and sequential method of analysing and interpreting data. The six stages of thematic analysis established by Braun and Clarke (2006) (familiarization with data, generation of initial codes, searching for themes, reviewing themes, defining and naming themes) were used to analyse and interpret the data. A description of these stages as they related to this study follows.

The first stage, familiarization with data (Braun \& Clarke, 2006) was achieved through a multiple stage transcription process. Audio recordings of individual interviews, defined by Braun and Clarke as "data items" (p. 79) were first transcribed by hand then put into typewritten form. Once data was in typed form, it was reread. This process set the stage for analysis as data was familiar to the researcher in preparation for coding.

The second stage, generation of initial codes (Braun \& Clarke, 2006) was started by noting ideas, questions and interesting items arising from the data in the margins of the handwritten and typewritten transcriptions as well as in a notebook devoted to this purpose. Twelve codes were initially identified; these were later collapsed into ten codes. The codes included: good intentions, belonging, curriculum content, parent involvement in holiday planning, replication of practices, barriers identified by ECEs regarding curriculum 
implementation, lack of knowledge, and token approaches to holidays, policy issues and professional opinions.

The third stage, searching for themes (Braun \& Clarke, 2006) was initiated by printing out data in large font format allowing data items to be cut apart into data extracts, defined by Braun and Clarke as "an individual coded chunk of data" (p.79). Multiple pages of flip chart paper were posted onto the wall, establishing a visual way of manipulating the data. The researcher was able to work with sections of data to determine the best fit for each piece of data. Through this process, clusters of data were no longer connected to individual participants but started to represent unnamed but similar clusters of codes. As these themes emerged, clustering of codes and identification of themes was initiated. Notations were made when data potentially represented more than one than one code. A notebook was kept to record ideas and questions that emerged throughout the analysis process.

The list of codes also included descriptions of data (exclusions) that would not fit the code (Boyatzis, 1998). An example would be the exclusion of descriptions of specific holidays for the coding of replication of holiday practices. While there might be detail regarding a holiday within the data, the coding process was designed to capture references to the process of curriculum planning around holidays rather than the content. Therefore, if there was no reference to the process of planning, the data would not be coded for replication of holiday practices.

Once themes began to emerge, the fourth stage of analysis, reviewing of themes (Braun \& Clarke, 2006) began. Through this process, some data extracts were moved, others were duplicated to reflect the multiple ways the data could be interpreted. The process of naming of themes occurred concurrently with their definition with further refinement of naming occurring 
through the process of analysis. The creation of large visual representations of data representing themes provided a strong visual basis for the findings of the study.

\section{Authenticity and trustworthiness.}

It was important to establish confidence in the findings through qualitative rigour (Thomas \& Maglivy, 2011). Rigour in qualitative research can be compared to reliability and validity in quantitative research (Thomas \& Maglivy, 2011). The following strategies supported the achievement of rigour within this study: The thematic analysis process was followed sequentially (Braun \& Clarke, 2006). General, non-identifying information about the setting and the participants was included in the findings section (Thomas \& Magilvy, 2011). Particular attention was paid to clarification of participant ideas during the interview process and through a two step transcription process which included returning to listen to audio recordings as needed to ensure accuracy of data. Braun and Clarke (2006) speak to the importance of writing throughout the analytical process rather than only at the end; they describe "writing as an integral part of analysis" (p. 86). The researcher established a journal devoted to this task.

\section{Ethical considerations.}

Because the researcher works in a management position within the Children's Services Division of the City of Toronto, it was important to avoid any perceived ethical issues. The study did not recruit participants currently working in ECEC programs within the City of Toronto. The researcher is identified to the participants as a graduate student in the Early Childhood Studies Department of Ryerson University. The study has been approved by the Ryerson Ethics Board (Appendix A). All participants reviewed and signed a release form (Appendix C). 
Participants were not identified by name within the study. This strategy is consistent with recommendations made by Mitchell (2009) when studying topics that may involve prejudice. Information requested from participants was limited to professional experience as an ECE and a general description of location of practice. Participants were welcome to provide additional information. The REB protocol allows data related to ethnicity and gender to be collected. Interviews were conducted in a professional setting or in a space mutually agreed upon by the participant and the researcher.

As discussions about social justice issues may give rise to questions for participants that would be beyond the scope of this study, information on relevant community resources was available to participants who expressed interest. This one-page handout included contact information for the Ontario Human Rights Tribunal, Community Legal Clinic, Children's Aid Society, Peel Family Services, and Ministry Of Education (Licensing). Participants were responsible to determine whether they want to pursue a particular issue or concern (Appendix D). This situation did not arise during the interview process so resource list was not shared with participants.

\section{Researcher perspective and positioning.}

Through the course of my personal and professional lives, my awareness of social justice has evolved into a commitment to understand and combat injustices. This dedication reflects my observations of racism, prejudice, and exclusion based on race, culture, gender, socioeconomic status, and disabilities. My extended family has reflected multiple cultures and races for three generations. I have observed the effects of racism and bias in both overt and hidden forms throughout my professional and personal life. Given that theory can seem out of reach for ECEs 
immersed in day to day work with children and families, one of the goals of this work is to bring the views of practitioners to the forefront and to contribute to the development of shared language and values related to diversity. As a researcher, I am aware of the importance of recognizing my own assumptions, values and biases, recognizing what McAllister (2001) refers to as "a dance with the data, moving between subjectivity and objectivity as experience supports interpretation while objectivity allows the story to emerge from the data" (p. 38).

My own professional journey as an ECE within community, educational, and government contexts highlights for me the need for Canadian research in this area. This research provides an opportunity to provide a glimpse into practice from a research perspective and to support the integration of theory into day to day practice. 


\section{Findings}

The findings tell the story of five Early Childhood Educators and how they perceive social justice, multiculturalism, and the role of families related to cultural holiday practices within the Early Childhood curriculum. Interview questions (Appendix C) were designed to elicit professional reflections, opinions, and recommendations on these topics. All quotations are the words of the participants except where cleaned or edited for readability. While the researcher took an inductive approach to the data analysis, it is understood that the analytic process is influenced by the researcher's experience so the strong literature support for the themes reflects both the data and the development of the researcher's lens through this process.

While each participant brought her own history and perspective as an educator of young children to this study, a commitment to social justice for families and children was also woven throughout these individual stories. Some participants described a reality where their own preferred practices, informed by social justice beliefs, were not consistent with the established philosophy or traditions within the Early Childhood Education and Care (ECEC) settings where

they have worked. Families were described as playing at most, a peripheral role in the design and planning of cultural holiday celebrations. The lack of professional discussion about social justice within ECEC and the value of meaningful and accessible professional development opportunities related to social justice and cultural holidays also emerged as strong themes throughout the data.

The three main themes identified through analysis were Belonging, Curriculum Approaches, and Systemic issues. Each theme incorporated at least three subthemes or codes. Theme 1, Belonging included good intentions and belonging. Theme 2, Curriculum Approaches 
included curriculum content, communicating with parents about the curriculum, and replication of practices. Theme 3, Systemic Issues included barriers, lack of knowledge, token approaches, policy issues and professional opinions. Detailed descriptions of codes are included in Table 2.

\section{Belonging}

A citizen, who is deeply connected with his/her roots and culture [and] has a sense of belongingness and connectedness. It aspires for children to maintain their roots and identity with their place and culture and at the same time, to become world citizens by being autonomous and self-reliant, able to function outside their local community.

$$
\text { Papatheodorou, 2010, p. } 6
$$

This theme included the sub-themes of good intentions and what belonging means. Without exception, all participants expressed a sense that the implementation of holiday practices in Early Childhood Settings reflects good intentions. The overall themes reflected the voices of the participants as they expressed a wish to respect and include families, the demographic makeup of their communities, and the idea that feeling a sense of belonging was important.

Tasmin related belonging to multiculturalism, emphasizing that the awareness of diversity and inclusion extends to all children and their families.

...It is like being aware of these children's lives, of their families, of their histories and the role we play in that, in nurturing their growth and their development so for me multiculturalism is awareness, it is not necessarily about different ethnicity, skin colours or holidays. It is about being aware of every little detail, similarity... 
Carin spoke at length about her sadness in not being able to provide support to a family who felt alone in a rural community because of their language, culture and race. The family were second language learners. The children attended the child care within this community, one in which they were the only non-white children. There had been very little change in the population and families that had lived there for generations. These children were the only non-white children in the child care where they didn't feel at home.

They stayed in that community and that school and that child care centre for only four months and then they withdrew... The parent said to me that in the community as a whole, not necessarily the centre, they felt isolated.... It was heartbreaking, three and four year old children feeling isolated in a community.

Tasmin spoke of belonging in the context of social justice:

I think the main thing is that however you live our life that you feel comfortable and accepted in the environment. So I mean that can be about so many things. I think ... social justice or justice in a social context is when everyone and everybody can function in the social world with some degree of freedom and safety - they can say what they think, they can wear what they want to wear.

Laura refers to promising and successful programming in the context of outcomes for children and families:

[You] can't base it on any program plan, I can say it [the program] would be successful in bringing in various different [children of] multi-ethnic background under one roof, in one program, and everyone plays and is happy and comes away from our program loving it and feeling included and being a part of [it], then we have done our job to make everyone fit in and no one is centred out because of the colour of their skin or the beliefs or the food that you eat. 
Tasmin identified her concern that professional development be planned with the awareness that day-to- day curriculum practices are not designed with ill will in mind:

A lot of these things that could be oppressive or marginalizing are done with really good intentions - they come from a good placethe intentions are there and that is why it is hard to flip the conversation because it is not about accusing the person of being those things, of marginalizing or oppressing, it is about the bigger conversation which is what I am talking about for workshops or professional development.

\section{Curriculum Approaches}

The positive outcomes that can be produced by respect for diversity initiatives require time and persistency. Superficial or short-term approaches may increase rather than reduce children's stereotyping and prejudice.

MacNaughton, 2006, p. 49

The most common curriculum approach to cultural holidays described by participants was replication of activities from year to year. These were generally reflected in theme -based programming, an approach described earlier in this paper. Opportunities for reciprocal planning and learning about holidays with families and children were generally described as possibilities rather than realities. Sara used the phrase "exploration of celebration" to describe how teachers might experience what a positive and unlimited discussion on holiday practices might look like.

The annual production of standard holiday celebrations was strongly connected to theme based (preplanned) programming while a curriculum approach which responded to children`s interests was described as a more fluid or flexible process. This contrast can be seen below in the following responses. 
Tasmin described the way December holidays were celebrated within an infant room. This tradition was described as well established but not something based on parent collaboration or a team plan. As a new ECE, she did not experience any discussion or introduction to the holiday plans; the traditional ways were not questioned. This is evident in the following excerpt:

In my experience it wasn't really questioned. I went along with it instead of speaking out...we took pictures of infant[s] in front of Christmas tree or Menorah and made that into a gift for the parents... No discussions, no options. There were only two options, the Christmas tree or the Menorah and the kids got one or the other...

Carin talked about planning for holiday celebrations based on the variations in program planning that she has experienced through work as a supervisor and a consultant to centres in a variety of suburban and rural communities. She touched on the relationship between curriculum approaches and holiday plans.

I don't know that it is always a conscious plan. It depends on the centre and it depends on the pedagogical approach of the centre. Some sites, if they are theme based, they tend to go by the dominant celebrations within their community, Halloween, Easter, Thanksgiving; whereas if they are more emergent based and they are in a community that has a lot of cultural diversity reflected in their population it might be different. There might be more recognition of celebrations that they are having at home or preparing for...

Sara spoke of what she refers to as an emergent philosophy: "Had the children brought up something about the holidays, we would have explored that... Our team looked at what the kids were doing. Tried to build stuff they were interested in so there was no sort of rule." 
The opportunity to explore and develop cultural holidays collaboratively with children and families was touched on by the majority of participants. It has been coded as planning with families. Laura described the possibility for children to share their knowledge of holidays with others. "Why not expose it to everyone - to learn, to share, and acknowledge knowledge. What have you [as a child] been doing in your household for three or four years? You could be teaching me something...teach [me] about holidays, share knowledge back and forth." The idea of parents as a resource was highlighted by Giulia who asks parents about stuff that they do at home, specifically if they are new to Canada...and parents can be a great resource and we totally forget that sometimes I think...if you want the parents to feel part of the program as well, it is their children that we are working with, their children, it is in your best interest to include them, right?

Sara framed this discussion in terms of beginning to talk to families about their home and community practices.

I am interested in social justice but I don't want to be throwing things at the kids that aren't coming from them, telling what they should believe... I don't know, you want to start in the community, in the families, which I guess is why holidays might make sense, if families [or] things that people do at home, if there is a celebration ... in their homes, there are many ways of talking about it.

Another view of collaboration with children over the traditional December holiday season was offered by Tasmin who described what December could look like within an emergent curriculum approach. The holiday season wasn`t necessarily the focus, unless initiated by the children. 'If it doesn't emerge out of children's interests, not doing it. If kids want to talk about 
sharks at Christmas time, that's what we're doing. No one is talking about making Christmas presents."

Laura highlighted the decision of a program to respect members of multiple ethnic community members by focusing on themes other than holidays. "We do not focus on one culture or many, or it can just be fun, under sea, colours, fun. But not based on culture. Not offending anyone's culture, not stepping on anyone's toes. We just keep it simple right across the board." It is interesting to note that families were not part of the decision to omit cultural holidays from the program.

In the programs described above by Tasmin and Laura, one might not see any holiday symbols during the month of December. While the approaches were different, the similarities merit examination. The first example reflected children's interests. Holiday symbols might be introduced by children and subsequently explored by practitioners. The second approach (described by Laura) consciously omitted holiday symbols and planned holiday celebrations as a way of respecting socio-ethnic backgrounds of families. Laura referred to the "rules" that teachers could not initiate activities related to specific holidays, while children and families were neither encouraged nor discouraged from sharing their own holidays.

The idea that a lack of resources and professional knowledge could be a barrier to an effective social justice curriculum was approached by participants in two distinct ways which are identified here as the concrete knowledge approach and the in depth discussion approach. In most cases, preferences for each approach were mutually exclusive. The first approach, concrete knowledge was articulated in terms of practical information on actual cultural holidays. Giulia described the response from the centre staff when such a resource became available to them: 
I got a calendar once from a conference that I went to and it was every single holiday on every single month that could possibly be celebrated anywhere. And I brought it back to my centre and every single teacher said "thank God we have this - this is so great—now we know everything, now we don't skip over anything ....

Laura shared her wish for such concrete information on holidays and her hope that it could be part of professional development. She hoped for "knowledge, more exposure to knowledge, information, different beliefs and cultural ways, everything would help me have a better understanding of different holidays ... and I could take that knowledge and enrich our programs which I would love to do."

Participants whose experience reflects a systemic view talked about their need for a deep discussion rather than concrete information. Tasmin talked about what would work for her at this point in her career:

I would be interested in a workshop about the bigger picture and really talking about what we think, you know talking theoretically about how we think, how we-what kind of bigger ideas guide our practice and how we can start having more conversations about ... those ideas. You know I'm not really that interested in, you know, somebody telling me [to] celebrate all the kids holidays' and make sure you celebrate every child in the room.

The idea of hands on resources, information on holiday practices, program samples, as well as the appropriate way to celebrate holidays was put forward by Laura and Giulia both of whom work directly with children. Sara stated that as a new ECE and teacher, she wanted more than theory; she would like practical knowledge "for me, I would want workshops and I would like to 
see ECEs doing the work with the students, finding practical ways of doing [social justice work]."

Sara identified practical discussions as important but in terms of social justice. She felt confident that others who had successfully implemented programs reflecting social justice principles could share their knowledge about implementation:

Yes, because I feel it is happening and I know that it is possible and working with other people interested in social justice, even hearing about their ideas, hearing about things that worked, then I feel confident to try it - if it worked with them, their students, maybe it will work with mine and I feel more likely to try it if it worked for someone else.

The wish for in depth discussion about holidays was articulated by Tasmin who spoke about the culture of ECEC in terms of replication of practices and the challenges of introducing another approach:

it's not the individual, it's a whole kind of culture of practice that has been going on and on for so long and it's hard to start the conversation and start to reflect that ok, there might be another way to do this ...

Tasmin expressed confidence that if we can start what she terms as the "bigger conversation" about values and biases, that ECEs would be open to exploring these topics:

I certainly think that once we start having the discussion, a lot of practitioners, a lot of ECEs would probably be pretty happy to talk about something beyond that basic recipe...you know it could be really challenging for a lot of them to have that conversation but I think if they could get through that first challenge that they would probably get to like to have that more in-depth conversation. 
The final code within the cluster of Curriculum Approaches captured the range of ways that participants talked about the replication of practices within the curriculum. The most common approach to cultural holidays was described as the unquestioned activities which are repeated without question both on a daily basis and in relation to cultural holidays. In reference to curriculum and social justice discussions, Tasmin referred to the "[curriculum] recipe....the power point kind of [training] "do this ... think this ...." In response to a probe regarding social justice discussions among staff, Carin referred to a typical discussion reflective of ECE training completed 20 years ago, “... how to cut out my dinosaur and get you to paint it in red, and not questioning or critical discussion about what are we doing with these kids?" She linked the lack of diversity in day to day activities with the lack of discussion about holidays. "And I think that leads to the celebration of holidays. If they (ECEs) immerse themselves more diversely in their curriculum and their accessible resources, whether it is the books, play materials, whatever, it will lead to greater discussion." She described the isolated holiday celebrations as "tokenistic". Derman-Sparks (2009) uses the term "add on multiculturalism" to refer to approaches where activities outside of the European American culture are considered to be special events.

Because add-on multiculturalism is organized around concrete and nonthreatening activities (e.g., food, holidays, songs), many teachers find it easier to make these superficial gestures or window dressing changes rather than to truly transform their curriculum (p. 131)

The descriptions of symbols used to represent cultural holidays included posting pictures referring to a holiday, the use of congratulatory sayings, representations of the Menorah, or ceremonial items used for Kwanzaa. Carin described her experiences:

They (cultural holiday celebrations) are typically holidays that are celebrated by the Christian faith. There are a lot...what I haven't 
seen is a lot of diversity as far as formal celebrations. Some centres, I've seen integrate very tokenistically, [for] holidays, they may have a poster that celebrates Kwanzaa or something but not anything to address or talk about that holiday celebration. I've gone to centres in the past few weeks and the most recent one would be the Chinese New Year where they have Kung Hei Fat Choi on the doors but there is no evidence that the New Year is being celebrated within the centre. There is no visual representation; the staffs [members] are not talking about it to my observation.

When these symbols are used in isolation to represent cultures other than the North American norm, they are referred to as "token gestures" or "tourist approaches" (MacNaughton, 2006).

References to symbols were present in all in interviews. Of interest is that in some settings, symbols are deliberately not used because of their strong connection to holidays. In Laura's description, symbols representing any religious holiday were deliberately absent from the curriculum. The more common approach; however was that symbols were used to represent diverse holidays.

\section{Systemic Issues}

Much is left to the intuition and professionalism of early years professionals who must make sense of the discourse of cultural diversity and work out what an inclusive curriculum truly entails.

Ang, 2010, p. 45

The theme of systemic issues reflected both the visions of ECEs about possibilities, and barriers related to implementing a socially just curriculum. A wide range of ideas were presented by participants ranging from the practical to the systemic. This is reflective of Ang's 
(2010) argument that there is little support for the individual practitioner to determine how to implement an inclusive curriculum. The majority (three) of the participants have completed university degrees related to ECE. Their responses took a more systemic view than the college graduates.

Barriers and possibilities were discussed on a number of levels ranging from the expectation that ECEs achieve professional development training after a full day of work with children or the expectation that an ECE deliver a prescribed curriculum to the ways in which ECEs might become engaged in a conversation about social justice. These issues were reflected in the participants' thoughts on the design of a professional conference for Early Childhood Educators focusing on cultural holiday celebrations and social justice.

The limited ability of an individual Early Childhood Educator to influence the practices of an established program emerged across themes. This subtheme of barriers acknowledges the lack of common understandings of social justice, and cultural holiday practices, and the strength of established or prescribed practices. Thoughts on how these challenges can be overcome have been captured under the subtheme possibilities.

The range of approaches to social justice, multiculturalism and cultural holidays described by participants demonstrated that conversations among practitioners on these topics are limited. All participants identified their wish to have more knowledge about cultural holiday practices; some participants stated that social justice needs to be added to ECE training. The need for pre-service training to provide students with strategies for supporting diversity which goes beyond a superficial acknowledgement of diversity was identified by Carin:

I think in the pre-service training, it is almost tokenistic in that delivery. There is discussion about the importance of diversity and 
the importance of including various cultural holidays but ECEs are not always intimately exposed to or given strategies for how to do that if it is beyond what their knowledge level is.

Diversity in Early Childhood Education and Training (2011) describes competency in a systemic way with the ECE being part of an overall system of support from the team level to the political and pedagogical level. At the level of the individual practitioner, being and becoming 'competent' is a continuous process that comprises the ability to build on and contribute to a body of professional knowledge, acquire both practical and reflective skills, and develop a professional attitude.

In the local world of ECE, professional development opportunities for Early Childhood Educators were generally limited to after work or weekend sessions which were often funded by the individual practitioner, generally an individual responsibility. Tasmin proposed that if we want to have a conversation with ECEs about social justice, thought needs to be given to the needs of the educator within the demanding world of ECEC. "It's so hard to bring these conversations to the practitioners' world because they're just barely staying afloat doing what they do." She described a starting point for a discussion about social justice intertwined with her concerns about how the typical after work, self-funded training model created barriers:

Well, I mean in an ideal situation there would be a time where ECEs would take a day away from their classroom, be paid for it, be fed, be comfortable and really be given a space and time to go there [to discuss social justice] because you could imagine, going after work, after eight or nine hours working in a child care centre, paying however much money to go to a two hour workshop where you would have to sit and start talking about how you are marginalizing children and families. 
Carin reminded us that when planning for professional development,

We need a baseline of knowledge.... We could be presenting what we think they know rather than hearing what they want to know. As the person co-ordinating the conference, it might not be their vision, but it could be used a jumping board for a shared vision.

The participants`responses reflected the importance that professional development supporting inclusion and diversity be guided by a clear systemic vision and quality anti-discrimination resources in order to meet the needs of the system as well as practitioners.

\section{Summary of Findings}

In conclusion, in speaking of her motivation for integrating social justice principles into her teaching, Sara captured the idea that we can support all children to become leaders:

I honestly think that a social justice focus makes education so much more; I mean it really prepares kids to feel like they can be agents of change in the world and so that if at such a young age, think about how far those kids could come. So many kids feel they have no power, can't do anything and I think you are doing this kind of work with them at that young age, you can really inspire them, empower them. And I am not sure if this is the way that we are moving right now, but I think that we should.

This chapter has identified three central themes arising from the data obtained through semi-structured interviews with five Early Childhood Educators sharing their thoughts about social justice, multiculturalism and cultural holiday practices in the context of families and the curriculum. These themes of Belonging, Curriculum Practices and Systemic Issues reflect perceptions representing a wide range of professional practice, personal experience and Early 
Childhood communities. This exploration will continue to unfold in Chapter 6 as these themes are discussed in more detail in relation to the literature.

\section{Organization of Results}

Table 2: Definition of Codes

1. Curriculum design

Description: holiday plans tied to curriculum approach

Exclusions: specific holiday descriptions

2. Good intentions

Description: mention of wish to respect and include families

Exclusion: specific activities or actions

3. Barriers to implementing socially just holidays

Description: lack of resources, training opportunities

Exclusion: personal beliefs

4. Communicating with parents about holidays

Description: level of discussion with parents about cultural holidays

Exclusion: Not reference to overall parent involvement strategies

5. Replication of traditional practices

Description: established holiday practices are followed annually without question

Exclusions: Not a description of specific holiday(s) 
5. Stated lack of knowledge about customs specific to other cultures

Description: Reference to lack of knowledge or resources

Exclusions: Not reference to centre policies re holidays or curriculum approach

6. Policy issues

Description: Expressed gap between professional/ personal

beliefs and agency policies

Exclusions: Any comments expressing a bias toward a holiday

7. Token approaches to multiculturalism and holiday practices

Description: Identification of holiday symbols or play materials representing a particular holiday

Exclusion: Not referring to a curriculum approach

8. Belonging

Description: Stated wish for families to feel a sense of belonging

Exclusions: Not a wish for families to fit into existing practices 


\section{Discussion and Recommendations}

This qualitative study was guided by the overarching research question: How do Early Childhood Educators (ECEs) perceive social justice and multiculturalism within the Early Childhood Education and Care (ECEC) curriculum? The role of families in planning for holidays and identification of training needs were included in the interview questions. The research design framed this discussion in the context of cultural holiday celebrations. A poststructural lens provided a clear view of the power relations inherent within celebratory practices. The terms anti-discrimination approach or teaching for social justice are used interchangeably throughout this chapter to refer to teaching approaches that promote equity, combat marginalization, racism, prejudice and imbalances in power (Delpit, 2006; Pohan, 2000).

\section{Discussion of the Findings}

Integration of social justice throughout the ECEC curriculum has been identified as a key component of quality by Diversity in Early Childhood Education and Training \& International Step by Step Organization (2011); as well, the literature describes teaching for social justice complex, layered and challenging (Rhedding-Jones, 2001; MacNaughton, 2006). This often results in curriculum design which emphasizes approaches to multiculturalism which are familiar and comfortable to the educators (Jacobson, 2003; Sensoy et al, 2010). These complexities and seeming contradictions are apparent throughout this study. This chapter will weave these related ideas together and discuss them with regard to cultural holiday practices within the ECEC curriculum including recommendations for practice and future research. 
The key themes in the literature related to social justice and cultural holiday celebrations are marginalization of families, token approaches to diversity and the patchwork of curriculum approaches that purport to champion diversity and equity. As discussed previously in this paper, cultural holiday celebrations are intertwined with equity and diversity (MacNaughton, 2006). Friendly and Prabhu (2010) in turn identify the importance of incorporating "best practices" (p.18) which support children in respecting diversity.

\section{Marginalization of families.}

The multiple references to Christmas throughout the data suggest that this established holiday has a strong influence on other December holidays. Its unquestioned presence or deliberate absence from curriculum plans as described by study participants supports this idea. This reinforces what Ang (2010) describes as the normal way of living versus a dissimilar or diverse way of living. This in turn can reinforce hierarchical or binary relationships between those who celebrate Christmas and those who don't. It is suggested that Early Childhood Educators increase their knowledge of significant holidays for multiple cultures throughout the year. If holiday celebrations are balanced and reflective of the wishes of parents, there is less risk

marginalizing families whose cultural and or religious celebrations are not focused on Christmas.

Participants consistently expressed a desire to create an environment that supports children and families and respects their individual cultures. These expressions ranged from enhancements to holiday practices to the other extreme which was the absence of holiday celebrations. Findings were consistent with what Ang (2010) describes as "the principles of 'equal opportunity', 'inclusivity', and 'meeting the diverse needs of children', [which] permeate the discourse of curriculum" (p. 45). There is strong support in the literature for questioning 
ECEC practices. The literature demonstrates the influence of Christmas on how Hanukkah is celebrated, the marginalizing nature of Aboriginal symbols used at Thanksgiving (Dorris, 2011) and the feelings of exclusion which can arise from exposure to Christmas symbols (Schmitt et al. 2010). If the strength of the accepted holiday norms and the stereotyped holiday images which form part of our holiday history is not recognized or questioned, families may not feel honoured or respected despite the best intentions of practitioners. This knowledge needs to be balanced by respect for the choices of individual families. While the literature focuses on Christmas as a dominant holiday, it may be an important part of a family's own culture. Jacobson (2002) notes that there is a gap between practices recommended in resource books and the practical strategies needed to develop these skills. Jacobson refers to books which recommend practical strategies (multicultural curriculum materials) as well as reflection on values related to diversity.

Derman-Sparks and Ramsay (2011) extend the discussion about culture from teachers to families. When teachers acknowledge that culture reflects identities and values independent of ancestry, they can better support families in this task. Most participants identified culture as unique to individual families which speaks to their understanding of the complexities of culture and race even within individual families. As Friendly and Prabhu (2010) suggest, ECEC programs can make a substantial contribution to the development of a "cohesive, socially inclusive society" (p. 23).

\section{The creation of the other.}

Cultural holiday celebrations that reinforce the differences between cultures can reinforce the idea that some groups are "the other" (Kumashiro, 2000). This most commonly occurs when the cultural events are seen as exotic in relation to accepted North American practices, 
reinforcing difference. The key to token approaches to diversity is the exotic and the different. The emergence of the theme token approaches during data analysis suggests that this approach is embedded in the culture of ECEC. Token approaches to holidays have been discussed in the context of the literature and the findings. It has been established that this approach to diversity can negatively impact children and families, even more so than if there were no attempts at diversity. MacNaughton (2006) describes these practices as superficial. The concern is that stereotypes are not always presented as negative but may serve to present an image of a group that on the surface seems positive but in fact has a negative impact on the group. It is important then that ECEs not only work with families within their programs but that they develop research skills to ensure that celebrations are appropriate, respectful and grounded in the practices of the broader community. The linkages between "othering" of a culture in this way have linkages to racism and colonialism (MacNaughton \& Davis, 2001).

\section{Curriculum Approaches}

Kagan and Kauerz (2006) link quality of Early Care and Education to curriculum, further strengthening the connections made between the content of holiday celebrations to social justice. MacNaughton's (2006) international overview entitled Respect for diversity places curriculum practices in the context of stated approaches, history and broad geographical location. The identification of these "broad schools of thought" related to diversity provides a framework for discussing the holiday approaches documented by participants. All participants were aware of the token approaches to diversity. Some participants contrasted these approaches with descriptions consistent with MacNaughton's (2006) anti-discrimination school of thought. These clusters of curriculum practices arising from the findings shed light on the numerous ways in which diversity is approached in practice. 
The connections made by participants between curriculum content and social justice is an important first step as it demonstrates their awareness of the relationship between theory and practice. It will be important to recognize and build on this connection rather than focusing on the gaps between practice and ideals. The divergent approaches to curriculum planning (themes versus emergent) is also an interesting finding as an emergent curriculum is by design more in tune with children, families and the community.

\section{Overcoming barriers.}

If Early Childhood Educators (ECEs) are the leaders and the decision makers within their classrooms (Jacobson, 2002), and the systemic goal is an anti-discrimination curriculum (MacNaughton, 2006), then they hold the key to success. In this study, practitioners identified a range of potential opportunities to support their practice as well as existing obstacles that could preclude achieving their goals to implement a curriculum that reflects social justice. Lack of resources, prescribed curriculum content and limited opportunities to develop skills combined to form the theme systemic barriers. The way in which each educator conceptualized training needs underscored the wide range of competencies regarding anti-discrimination teaching. This is reflective of the depth and complexity of the approach.

In order to successfully implement an anti-discrimination curriculum, MacNaughton (2006) identifies the need to have not only a commitment from practitioners, but also resources and support. The resources include skilled facilitators (Landreman et al., 2008); a safe space to confront the deep discomfort that can arise from challenging our own biases (Jacobson, 2003) and engagement in critical thinking at an institutional level (Ang, 2010). The idea that a systemic approach to social justice or social responsibility is necessary and that teaching 
practices reflecting social justice should be integrated throughout the curriculum is explored by authors including MacNaughton and Davis, (2001) and Derman-Sparks and Ramsey, (2011). Jacobson (2002) recommends that in order to achieve these goals, we need to both support and engage teachers in a process of self-reflection, connecting their own history and beliefs with their actions as teachers.

If we think of the professional journey that an ECE committed to social justice principles might experience, it could be conceptualized as a meandering path on hilly and sometimes rough terrain. Early Childhood Educators working toward social justice need leaders who have successfully made the journey and who can describe the vision, providing context, support and motivation along the way. If ECEs are not exposed to, or supported in developing a critical approach to teaching about social justice and diversity during training or through professional development, they may not take risks to implement new practices. They may then seek out the "recipe card" approach (DiAngelo \& Sensoy, 2010) or the tourist or tokenistic approach (MacNaughton, 2006) as the way in which they implement the curriculum. Jacobsen, (2003) refers to the layers of personal and systemic history that an educator must confront if they choose to truly transform their practices and teach for social justice.

The systemic approach to social justice teaching was associated with exposure to social justice curriculum content within degree and post-graduate programs. This finding is very positive as it demonstrates that the focus of post-secondary and post-graduate programs can support leaders who take a big picture view of social justice. It may also identify a gap in ECE curriculum content at the college level. This is, however, a weak connection due to the small sample size. It is also possible that ECE college curriculum may have changed since the participants in this study completed their training. 


\section{Suggestions for Future Research}

There are two divergent yet important directions for future research. One could focus on perceptions of parents about cultural holidays and social justice; the other would be to continue the work with practitioners. My recommendations focus on developing competencies for practitioners and strengthening programs.

Further enquiry into perceptions of Early Childhood Educators based on a broader range of participants would establish a foundation of knowledge for practitioner competencies. Participants representing a broader range of cultural backgrounds and the inclusion of male ECEs may yield additional insights or different results. A larger sample would strengthen results.

Opportunities could include an action research project conducted with Early Childhood Educators, perhaps in an ECEC setting co-located either physically or virtually with an educational institution. This research could serve two purposes: first, it would document the process of developing socially just and equitable holiday practices within the curriculum. Secondly, it could also identify accessible professional development opportunities that could be tailored to meet the needs of ECEs at all phases of their career. This is consistent with the recommendations of Sensoy et al. (2010) which suggest action research as one way that teachers can engage in reflection and curriculum change. The development of front line leaders throughout the ECEC system could be a worthwhile investment. These on site leaders could highlight connections between social justice and curriculum for teachers as well as families.

A mixed methods study may be useful in quantifying the relationship between curriculum approaches and the exposure of ECEs to social justice content at varying points within their 
training and career. A combination of quantitative survey data as well as qualitative interviews with ECEs could provide a wider view of curriculum practices.

\section{Implications for Policy and Practice}

Designing and delivering an anti-discrimination curriculum within one ECEC program is a complex undertaking. Making a systemic change is more daunting yet one cannot occur without the other. The challenge will be to support incremental changes which are consistent with a clear vision of anti-discrimination teaching in practice. ECEs will need support to situate their practice within the larger framework of social justice. Part of this process will be for each educator to be aware of her or his own cultural identity and how that influences their practice.

There is an opportunity for ECEC programs to engage in a critical review of their curriculum as it relates to social justice and provide leadership to others that is similar to the work done by DiAngelo and Sensoy (2010); and Jacobson (2002). This would achieve three key goals: demonstrating the anti-discrimination curriculum vision in practice, supporting practitioners as leaders and the development of accessible training opportunities. Leaders need to be and recognized as well as provided with opportunities to guide and influence others. The opportunity to meet diverse needs for knowledge and training identified by study participants could be met in this way. One needs to be wary, however of the desire to make this process concrete and measurable. Equity and fairness cannot be measured using a checklist or manual. Landreman, et. al (2008) caution that teaching social justice can seem deceptively simple if we rely only on activities and learning materials, If we ignore the importance of skilled facilitation, "we risk doing harm and perpetuating oppression despite our best intentions" (p. 9). Workshops may be effective in introducing the connections between social justice and curriculum but in 
order to support the vision of anti-discrimination curriculum, a plan for a sustained training model based on a shared vision is needed.

\section{Limitations of the Study}

Recruitment was a very challenging process and exceeded the projected time frame. Hundreds of potential participants were informed of the study either through their local professional network, personal contacts or through a presentation by the researcher. This extensive recruitment strategy yielded only five participants, a relatively small sample. All participants were women and predominately identified as being of Caucasian heritage. Participants were not asked about their motivation for volunteering for this study however it can be surmised that their motivations reflect a level of altruism consistent with a belief in social justice. It could be inferred that their commitment to social justice indeed may have influenced these findings.

This study focused on perceptions of ECEs with experience within the Greater Toronto Area. Four out of five participants had experience in urban and/or suburban settings while two participants had experience in rural settings. Perceptions of participants were contextual to their individual experiences and were not reflective of urban or rural communities specifically.

As an ECE who has been immersed in the field for over 25 years. I am cognizant of the limitations of ECEs working within organizational structures and I know how challenging the field is and how hard educators work. At the same time, I have endeavoured to maintain an awareness of my own values about social justice and the potential bias that this could bring to the study. 


\section{Significance of the Study}

This study is unique in that it examines the perceptions of Canadian practitioners using international (MacNaughton, 2006) and interdisciplinary literature. It brings the voices of practitioners to the forefront of the discussion about families, holidays, multiculturalism and social justice. The findings are grounded in the day to day experiences of ECEs as they talk about balancing their own beliefs within their professional practice in the context of established curriculum in their workplaces. Of particular interest are the ideas for professional development identified by participants, especially the need to develop a range of training that would support ECEs at varying points of their careers. One important suggestion was that ECEs could have an opportunity to influence the development of professional development opportunities, to share their thoughts on their own current knowledge and future goals in the area of social justice and curriculum. The findings demonstrate the linkages between social justice, curriculum and professional development from the perspective of participants.

\section{Summary and Conclusion}

The goal of this research study has been to examine social justice in relation to cultural holiday celebrations as perceived by Early Childhood Educators. The findings provide knowledge about these practitioners and how they view social justice and multiculturalism. Also of importance is the identification of systemic barriers faced by practitioners who wish to teach for social justice. "Anti-bias/multicultural teaching is not a matter of simply carrying out a collection of activities. It is a complex of large and small decisions that reflect our life histories, beliefs, and knowledge about children and the contexts of their lives" (Derman-Sparks and Ramsay, 2011, p. 11). 
One of the underlying motivations for addressing this topic was to answer the seemingly simple question that I hear progressive leaders in ECEC quietly asking each year as December approaches. This question is often framed as "what are we going to do about the holidays?" I have stopped to reflect on this question at different times during this study. My thoughts began to crystallize while reading the literature and were affirmed by analysis of the findings. The celebration of cultural holidays is not really the problem but neither is it the solution. If the celebration of non-dominant holidays is the only action taken to promote inclusion and fight racism, then it becomes tokenistic and marginalizing. Leaders in ECEC who commit to the integration of social justice principles throughout the curriculum can be confident that they will find their own respectful and inclusive holiday rhythms throughout the year.

It has been an enlightening and humbling experience for me as a researcher to be entrusted with the thoughts and voices of the participants. I hope that Early Childhood Educators who participated in this study as well as those in the field will be engaged in this discussion and encouraged to continue to work toward their ideals. I also hope that it provides a basis for future research into ways that we can support ECEs to recognize and promote socially just curriculum within Early Childhood Education and Care settings. 


\section{References}

Abramitzky, R. Einav, L. \& Rigbi, O. (2010). Is Hanukkah responsive to Christmas? The Economic Journal, 120 (545), 612-630. doi: 10.1111/j14680297.2009.02305.x

Ang, L. (2010). Critical perspectives on cultural diversity in early childhood: Building an inclusive curriculum and provision. Early Years, 30(1), 41-52.

doi:10:1080/09575140903562387

Banks, J. A. (2008). An introduction to multicultural education. Boston, MA: Pearson Education.

Belk, R. (1993). Materialism and the American Christmas. In D. Miller (Ed.), Unwrapping Christmas (pp. 75-104). New York: Oxford University Press.

Boyatzis, R. E., (1998). Transforming qualitative information: Thematic analysis and code development. Thousand Oaks, CA: Sage.

Bramadat, P. (2001). Shows, selves and solidarity: Ethnic identity and cultural spectacles in Canada, Canadian Ethnic Studies, 33(3), 78-98. Retrieved from: http://search.proquest.com.ezproxy.lib.ryerson.ca/docview/215639324/abstract

Britzman, D. P., Santiago-Valles, K., Jimenez-Munoz, G. \& Lamash, L. M. (1993). Slips that show and tell: Fashioning multiculture as a problem of representation. In C. McCarthy, C. \& W. Crichlow (Eds.), Race, identity and representation in education (pp. 188-200). New York: Routledge.

Burnett, B. M. (2001). Coming to terms with culture and racism. Contemporary Issues in Early Childhood, 2(1), 105-109. Retrieved from:

http://www.wwwords.co.uk/rss/abstract.asp?j=ciec\&aid=1541

Byrne-Armstrong, H. Higgs, J. \& Horsfall, D. (Eds.), (2001). Critical moments in qualitative research. Oxford, U.K.: Butterworth-Heinemann.

Cannella, G. S. (1997). Deconstructing early childhood education: Social justice and revolution. New York: Peter Lang.

City of Toronto. (1998). Guidelines for responding to racial incidents in child care. Retrieved from: http://www.toronto.ca/children/pdf/anti_racism.pdf

City of Toronto. (2011). Toronto operating criteria. Retrieved from: http://www.toronto.ca/children/operators/index.htm

Clark, D., \& Shimoni, R. (2000). Anti-bias Education and a Canadian national identity: Is there a connection? Canadian Journal of Research in Early Childhood Education, 8(2), 55-59. 
Davis, K. (2009). Unmasking cultural identities: Challenges for white early childhood educators. In G. MacNaughton \& K. Davis, (Eds.), "Race” and early childhood education (pp. 113125). New York: Palgrave MacMillan.

Dei, G. J. S. (1996). Anti-racism education theory and practice. Halifax, NS: Fernwood Publishing.

Dei, G. J. S. (2003). Communicating across the tracks: Challenges for anti-racist educators in Ontario Today. Orbit, 37(2/3), 2-5. Ontario Institute for Studies in Education.

Delpit, L. D. (2006). Lessons from teachers. Journal of Teacher Education, 57(3), 220-231. Retrieved from: http://journals2.scholarsportal.info/details.xqy?uri=/00224871/v57i0003/220_lft.xml

Delpit, L. D. (2006). Other people's children: Cultural conflict in the classroom. New York: The New Press.

Derman-Sparks, L., \& the A.B.C. Task Force (1989). Anti-bias curriculum: Tools for empowering young children. Washington, DC: National Association for the Education of Young Children.

Derman-Sparks, L. (2002). Educating for equality: Forging a shared vision. In E. Lee, D. Menkart, \& M. Okazawa-Rey (Eds.), Beyond heroes and holidays: A practical guide to K-12 anti-racist, multicultural education and staff development (pp. 2-6). Washington, DC: Teaching for Change.

Derman-Sparks, L., \& the A.B. C. Task Force (2003). Holiday activities in the anti-bias curriculum. In C. Copple (Ed.), A world of difference (pp.155-156). Washington, DC: National Association for the Education of Young Children.

Derman-Sparks, L. (2009). A framework for culturally relevant, multicultural and anti-bias education in the twenty-first century. In J.L. Roopnarine \& J. E. Johnson (Eds.), Approaches to early childhood education (pp.120-146). Upper Saddle River, NJ: Pearson.

Derman-Sparks, L. \& Ramsey, P. G. (2011). What if all the kids are white? Anti-bias multicultural education with young children and their families. New York: Teachers College Press.

DiAngelo, R., \& Sensoy, O. (2010). OK, I get it! Now tell me how to do it! Why we can't just tell you how to do multicultural education. Multicultural Perspectives, 12(2), 97-102. doi: 10.1080/152109600.2010.481199

Diversity in Early Childhood Education and Training \& International Step by Step Organization (2011). Diversity and social inclusion: Exploring competencies for professional practice in Early Childhood Education and Care. Retrieved from: 
http://www.decet.org/fileadmin/decet-media/publications/Diversity-and-SocialInclusion.pdf

Dorris, M. (2011). Why I'm not thankful for Thanksgiving. In E. Marshall \& O. Sensoy, (Eds.), Rethinking popular culture and media (pp. 100-105). Milwaukee, WI: Rethinking Schools.

Etzioni, A. (2000). Toward a theory of public ritual. Sociological Theory, 18(1), 44-59.

Francis, D. (1992). The imaginary Indian: The image of the Indian in Canadian culture. Vancouver, BC: Arsenal Pulp Press.

Friendly, M. \& Prentice, S. (2010). Can early childhood education and care help keep Canada's promise of respect for diversity? Occasional paper No. 23. Childcare Resource and Research Unit. Retrieved from: http://www.childcarecanada.org/sites/default/files/crru_op23_diversity.pdf

Friendly, M. \& Prentice, S. (2009). About Canada child care. Black Point, NS: Fernwood Publishing.

Friere, P. (1993). Pedagogy of the oppressed. New York: Continuum International Publishing Group.

Fryberg, S. A., Markus, H. R., Oyserman, D. \& Stone, J. M. (2008). Of warrior chiefs and Indian princesses: The psychological consequences of American Indian mascots. Race and Applied Social Psychology, 30(3), 208-218. doi: 10.1080/01973530802375003

Ghosh, R. (1996). Redefining multicultural education. Toronto: Harcourt and Brace.

Ghosh, R. \& Abdi, A. (2004). Education and the politics of difference: Canadian perspectives. Toronto: Canadian Scholars Press.

Higgs, C. \& McAllister, L. (2001). In H. Byrne-Armstrong, J. Higgs, \& D. Horsfall (Eds.), Critical moments in qualitative research (pp. 30-43). Boston: Butterworth-Heinemann.

Hobsbawm, E. (1983). Inventing traditions. In E. Hobsbawm \& T. Ranger (Eds.), The invention of tradition (pp. 1-14). Cambridge: Cambridge University Press.

hooks, b. \& Mesa-Bains, A. (2006). Homegrown: Engaged cultural criticism. Cambridge, MA: South End Press.

Jacobson, T. (2002). Prod and pry from the inside out: Ethnography of an anti-bias supportsupervision group for teachers of young children. In D. Rothenberg, (Ed.), Issues in early childhood education and dissemination of information: Proceedings of the Lillian Katz symposium. (pp. 171-178). Champlain, NY: Early Childhood and Parenting Collaborative. Retrieved from: http: //www.nccp.org/publications/pdf/text_810.pdf 
Jacobson, T. (2003). Confronting our discomfort: Clearing the way for anti-bias in early childhood. Portsmouth, NH: Heinemann.

Kagan, S. L. \& Kaurz, K. (2006). Preschool programs: Effective curricula. In R. E. Tremblay, R. G. Barr \& R. DeV Peters (Eds.), Encyclopedia on early childhood development (pp. 1-5) [online]. Montreal, Quebec: Centre of Excellence for Early Childhood Development: Retrieved from: http://www.child-encyclopedia.com/documents/KaganKauerzANGxp.pdf

Kelly, D. M. \& Brandes, G. M. (2001). Shifting out of "neutral": Beginning teachers' struggles with teaching for social justice. Canadian Journal of Education, 26(3), 437-454.

Kivel, P. (2011) Uprooting racism: How white people can work for racial justice. Gabriola Island, BC: New Society Publishers.

Kumashiro, K., (2000). Toward a theory of anti-oppressive education. Review of Educational Research, 70(1), 25-53.

Ladson-Billings, G. (1998). Just what is critical race theory and what is it doing in a nice field like education? Qualitative Studies in Education, 11(1), 7-24.

Landreman, L., Edwards, K., Balon, D., \& Anderson, K. (2008). Wait! It takes time to develop rich and relevant social justice curriculum. About Campus, 13(4), 3-10. doi: 10.1002/abc. 258

Lindsay, B. \& Scales. T. (2005). African Americans and international cultural observances in the higher education community. Journal of Black Studies, 35(5), 551-572. Retrieved from: http://journals1.scholarsportal.info/details.xqy?uri=/00219347/v35i0005/551_aaaicoithec. $\mathrm{xml}$

Litchman, M., (2006). Qualitative research in education. Thousand Oaks, CA: Sage Publications.

Mackey, E. (1999). House of difference: Cultural politics and national identity in Canada. London, UK: Routledge.

MacNaughton, G. (2005). Doing Foucault in early childhood studies: Applying poststructural ideas. London, UK: Routledge.

MacNaughton, G. (2006). Respect for diversity: An international overview. Bernard van Leer Foundation. Retrieved from: http://www.bernardvanleer.org/Respect_for_diversity_An_international_overview

MacNaughton, G. \& Davis, G. (2001). Beyond 'othering': Rethinking approaches to teaching young Anglo-Australian children about Indigenous Australians. Contemporary Issues in Early Childhood, 2(1), 83-93. Retrieved from: 
http://www.wwwords.co.uk.ezproxy.lib.ryerson.ca/pdf/validate.asp?j=ciec\&vol=2\&issue $=1 \&$ year $=2001 \&$ article=MacNaughtonCIEC2_1

MacNaughton, G. \& Davis, K. (2009). Discourses of "race" in early childhood: From cognition to power. In G. MacNaughton \& K. Davis (Eds.), "Race” and early childhood education (pp. 17-30). New York: Palgrave MacMillan.

Marshall, C. \& Rossman, G. B. (1989). Designing qualitative research. Newbury Park, CA: Sage Publications.

Marshall, C. \& Rossman, G. B. (2011). Designing qualitative research. Thousand Oaks, CA: Sage Publications.

Mayes, K. A. (2009). Kwanzaa: Black power and the making of the African American holiday tradition. New York: Routledge. Retrieved from: http://site.ebrary.com.ezproxy.lib.ryerson.ca/lib/oculryerson/docDetail.action?docID=103 26731

Merriam, S. (1998). Qualitative research and case study applications in education. San Francisco: Jossey-Bass.

Miller, D. (1993). A theory of Christmas. In D. Miller (Ed.), Unwrapping Christmas (pp.1-37). Oxford, UK: Oxford University Press.

Mitchell, L. A. (2009). Becoming culturally responsive teachers in today's diverse classroom. Paper presented at the American Educational Research Association Annual Meeting, San Diego, CA. Retrieved from:

http://www.eric.ed.gov/ERICWebPortal/search/detailmini.jsp?_nfpb=true\&_\&ERICExtS earch_SearchValue_0=ED505986\&ERICExtSearch_SearchType_0=no\&accno=ED5059 86

Munson, B. (2011). Human beings are not mascots. In E. Marshall \& O. Sensoy, (Eds.), Rethinking popular culture and media (pp. 149-152). Milwaukee, WI: Rethinking Schools.

Papatheodorou, T. (2010). Being, belonging and becoming: Some worldviews of early childhood in contemporary curricula. Forum on Public Policy: A Journal of the Oxford Round Table, 2010, 1-18. Accessed from:

http://forumonpublicpolicy.com/spring2010.vol2010./sprint2010archive/papatheodorou.p df

Perecman, E. \& Curran, S. R. (Eds). (2006). Handbook for social science field research. Thousand Oaks, CA: Sage.

Pleck, E. H. (2001). Kwanzaa: The making of a Black nationalist tradition, 1966-1990. Journal of American Ethnic History, 20(4), 3-28. 
Pohan, C. A. (2000). Part III, Creating multicultural classrooms: Practical ideas for teaching children about prejudice, discrimination, and social justice through literature and a standards-based curriculum. Multicultural Perspectives, 2(1), 24-28. doi:10.1207/S15327892MCP0201_7

Province of Ontario (2007). Day Nurseries Act. Retrieved from: http://www.elaws.gov.on.ca/html/regs/english/elaws_regs_900262_e.htm

Rhedding-Jones, J. (2000). Shifting ethnicities: Foreign whites and others working on anti-racist pedagogies in early childhood education. Australian Association for Research in Education, 2(2), 135-156.

Rhedding-Jones, J. (2010). Critical multicultural practices in early childhood education In S. May and C. Sleeter (Eds.), Critical multiculturalism: Theory and praxis (pp. 73-84).New York: Routledge.

Rodgers, B. and Cowles, K. (1993). The Qualitative research audit trail: A Complex collection of documentation. Research in Nursing and Health, 16(3), 219-226.

Rubin, H. and Rubin, I. (2006). Qualitative interviewing: The art of hearing data. Thousand Oaks, CA: Sage Publications.

Said, E. W. (1978). Orientalism. New York: Random House.

Schmitt, M., Davies, K., Hung, M. \& Wright, S. (2010). Identity moderates the effects of Christmas displays on mood, self esteem, and inclusion. Journal of Experimental Social Psychology, 46(6), 1017-1022. doi: 10: 1016/j.jesp.2010.05.026

Sensoy, O., Sanhera, R., Parmar, G., Parhar. N., Nosyk, L., \& Anderson, M. (2010). Moving beyond dance, dress and dining in multicultural Canada. International Journal of Multicultural Education, 12(1), 1-15 Retrieved from: http://www.google.ca/hws/search?hl=en\&client=dell-row\&channel=capsp\&ibd=5081205\&q=moving+beyond+dance + and+dining + in + multicultural+canada $\& S$ ubmit=Google + Search

Statistics Canada. (2011). retrieved from: http://www12.statcan.gc.ca/censusrecensement/2006/dp$\mathrm{pd} /$ prof/92591/details/page.cfm?Lang $=\mathrm{E} \& \mathrm{Geo} 1=\mathrm{CMA} \&$ Code $1=535 \& \mathrm{Geo} 2=\mathrm{PR} \&$ Code 2 $=35 \&$ Data $=$ Count $\&$ SearchText $=$ toronto $\&$ SearchType $=$ Begins $\&$ SearchPR $=35 \& B 1=A 11 \&$ Custom $=$

Troyna, B. (1987). Beyond multiculturalism: towards the enactment of anti-racist education in policy, provision and pedagogy. Oxford Review of Education, 13(3), 307-320. Retrieved from: http://jstor.org/stable/1050307 
Yeh, C. (2004). "In the traditions of China and in the freedom of America": The making of San Francisco's Chinese New Year festivals. American Quarterly, 56(2), 395-420. doi: 10.1353/aq.2004.0029 


\section{Appendix A- Recruitment ad}

\section{RYERSONUNIVERSITY}

SCHOOL OF EARLY CHILDHOOD EDUCATION

FACULTY OF COMMUNITY SERVICES

Master of Arts in Early Childhood Studies

\section{Advertisement for recruitment of study participants}

Are you interested in participating in a study exploring the linkages between cultural holiday celebrations and social justice?

This study will look at the development and practice of cultural holiday practices in licensed child care programs. Do these celebrations support and include all children and families? How do these practices promote or hinder social justice for children and families in the child care environment?

If you are an RECE with experience in licensed child care as a staff or consultant, I hope that you will consider participating in this study.

This study will be conducted by an RECE who is completing a Masters in Early Childhood Studies at Ryerson University. Confidentiality will be maintained regarding participant responses. The time commitment will be approximately one to two hours.

This research is being done to fulfill the requirements of a Masters degree.

If you would like more information on how to participate in this study, please contact May Jolliffe at may.jolliffe@ryerson.ca

350 Victoria Street, Toronto, Ontario, Canada M5B 2K3

Tel: 416 979-5306 Fax: 416 979-5239 TDD/TTY: 416 979-5138 www.ryerson.ca 


\title{
Appendix B- Consent agreement
}

\section{RYERSONUNIVERSITY}

\begin{abstract}
SCHOOL OF EARLY CHILDHOOD EDUCATION
FACULTY OF COMMUNITY SERVICES
\end{abstract}

\author{
Master of Arts in Early Childhood Studies \\ Ryerson University Consent Agreement
}

Study name: Social Justice in Early Childhood Practice: Do Cultural Holiday Celebrations support or marginalize families?

You are being asked to participate in a research study. Before you give your consent to be a volunteer, it is important that you read the following information and ask as many questions as necessary to be sure you understand what you will be asked to do.

Investigator: May Jolliffe, student, Masters in Early Childhood Studies Program, Ryerson University.

Research supervisor: Dr. Marni Binder

$$
\begin{aligned}
& \text { mbinder@ ryerson.ca } \\
& \text { Ryerson University }
\end{aligned}
$$

KHS-363

350 Victoria St. Toronto, ON

$416-979-5000 \times 7130$

Purpose of the study: The purpose of this qualitative study is to document what Early Childhood Educators (ECEs) think about cultural holiday celebrations within Early Childhood Education 
(ECEC) settings. The study is intended to gather information on holiday practices which will be analyzed in the context of social justice. Participants will not be evaluated on their responses. There is very little information about the experiences and thoughts of ECE staff about social justice, specifically holiday celebrations. Participants will be asked about their professional experiences and views on multiculturalism and cultural holiday celebrations in Early Childhood Education and Care settings.

The study format will consist of one interview for individual participants about one to two hours in duration. Questions will relate to multiculturalism and cultural holiday celebrations within the context the participants' professional practice. Participants will also be asked to share their views regarding whether cultural holidays promote or hinder social justice for children and their families in the child care environment.

Risks or Discomforts: The interviews would pose minimal risks. Participants may skip a question or terminate their participation in the interview or study at any time.

Benefits of the Study: The completed study will gather, document and analyze data regarding Early Childhood Educator's perceptions of cultural holiday celebrations and social justice in the context of Early Childhood Settings. A resource list of agencies will be provided should participants want to follow up on a topic identified in the interview. Participants in the study may find intrinsic value in being part of this research, however there is no guarantee of any individual benefit to participants. It is hoped that the information and knowledge generated by the study will help college faculty to determine future training and research directions.

Confidentiality: Confidentiality will be maintained. All records relating to this study will be under the care of the researcher until analyzed, then kept in a locked cabinet in the research 
supervisor's office at Ryerson. Recordings will be destroyed once transcription is complete. A coding scheme will be assigned to the data/ participants.

Incentives to participate: Participants will not be paid to be in this study.

Costs and /or Compensation for participation: There will be no cost associated with participation in this study.

Voluntary Nature of Participation: Participation in this study is voluntary. Your choice of whether or not to participate will not influence your future relations with Ryerson University. If you decide to participate, you are free to withdraw your consent and to stop your participation at any time without penalty or loss of benefits to which you are allowed.

At any particular point in the study, you may refuse to answer any particular question or stop participation altogether.

Questions about the study: If you have any questions about the research now, please ask. If you have questions later about the research, you may contact the researcher.

Principal Investigator: May Jolliffe.

Contact: may.jolliffe@ ryerson.ca

If you have questions about your rights as a human subject and participant in this study, you may contact the Ryerson University Research Ethics Board for information:

Research Ethics Board

c/o Office of the Vice President, Research and Innovation

Ryerson University

350 Victoria St

Toronto ON M5B 2K3 
Agreement:

Your signature below indicates that you have read the information in this agreement and have had a chance to ask any questions you have about the study. Your signature also indicates that you agree to be in the study and have been told that you can change your mind and withdraw your consent to participate at any time. You have been given a copy of this agreement.

You have been told that by signing this consent agreement you are not giving up any of your legal rights.

Name of Participant (please print)

Signature of Participant

Date

Signature of Investigator

Date

The interviews will be audio taped. I agree to have my interview audio taped for this study. Tapes will be destroyed once transcription is complete. 
Name of Participant (please print)

Signature of Participant

Signature of Investigator

Date 


\section{Appendix C-Semi-structured interview questions}

1) [Please] describe a cultural holiday celebration that has stood out for you as an Early Childhood Educator.

2) How would you define the term multiculturalism within the context of Early Childhood Education and Care?

3) Based on your professional experience, how have ECE teams developed plans for holiday celebrations?

4) What kinds of discussions have you had with families of children in your program about cultural holiday celebrations?

5) How would you describe social justice in the context of Early Childhood Education and Care?

6) If there was a conference workshop on social justice and cultural holidays, what do you think should be included in the session?

7) Can you make recommendations for training institutions and policy makers related to social justice and / or cultural holidays?

Revised 26-Sep-2011 


\section{Appendix D- Resource Material}

\section{Social Justice in Early Childhood Practice: Community Resources}

Association of Early Childhood Educators Ontario: http://www.aeceo.ca/

College of Early Childhood Educators:

http://collegeofece.on.ca/en/Public/Pages/default.aspx

Early Childhood Community Development Centre: http://www.eccdc.org/

Family Services York Region: http://www.fsyr.ca/index.html

Ministry of Children and Youth Services: http://www.children.gov.on.ca/

Ministry of Education: http://www.edu.gov.on.ca/eng/

Ontario Human Rights Commission: http://www.ohrc.on.ca/en

Family Services of Peel community resources: http://www.fspeel.org/Community$\underline{\text { Resources.pdf }}$ 